\title{
Aiming too high or scoring too low? Heterogeneous ethnic gaps in upper secondary enrollment and outcomes beyond the transition in France
}

\author{
Alessandro Ferrara*
}

May 24, 2021

\begin{abstract}
The children of immigrants tend to make more ambitious enrolment choices than native students after controlling for their lower social status and prior academic achievement. Few studies have explored heterogeneity in these ethnic choice effects by both social origin and previous achievement simultaneously, so it is unclear whether results are driven by specific immigrant-native comparisons. Moreover, most research does not investigate outcomes after the educational transition, so the long-term consequences of these educational choices remain unclear. Using French panel data from the 1995 and 2007 rounds of the Panel d'Élèves du Second Degré and focusing on the children of immigrants from Africa and Turkey, I investigate immigrant-native gaps in the decision to enrol in academic upper secondary education and in outcomes after the transition. I find evidence of positive ethnic choice effects. However, I also find that they were substantial only when comparing the most disadvantaged immigrant-origin and native students (low-performing and lower class students). After the transition, immigrant-origin students were more likely to be retained, less likely to further transition to the most prestigious track and less likely to complete a track leading to tertiary education. Analyses using counterfactual reweighting suggest that large portions of these gaps were explained by positive ethnic choice effects and by the long-term impacts of immigrant-native gaps in prior academic achievement. My findings indicate that ethnic choice effects are prevalent among academically fragile students and that policy should aim to close early gaps in academic achievement to limit their persistent effects over time.
\end{abstract}

*European University Institute, Department of Political and Social Sciences. alessandro.ferrara@eui.eu 


\section{Introduction}

The educational continuation decisions of students with an immigrant background have gained considerable attention from scholars. After accounting for socio-economic status and prior academic performance, the children of immigrants (henceforth referred to as "immigrant-origin students") are more likely to enrol in more demanding academic tracks compared to their native peers. This finding has been confirmed for several educational transitions, countries, and immigrant backgrounds (Denmark: Birkelund (2020); England: Fernández-Reino (2016); Jackson et al. (2012); Finland: Kilpi-Jakonen (2011); France: Brinbaum and Cebolla-Boado (2007); Germany: Dollmann and Weißmann (2019); the Netherlands: Van De Werfhorst and Van Tubergen (2007); Sweden: Jonsson and Rudolphi (2011); and Switzerland: Tjaden and Scharenberg (2017)).

The enrolment decisions of immigrant-origin students are generally perceived as an advantage because they are expected to lead to higher educational attainment (Jonsson et al., 2014; Kilpi-Jakonen, 2011). However, their academic performance tends to be lower than the one of native students and this could influence their educational attainment after the educational transition. Indeed, there are concerns about the true benefits of such ambitious educational choices, which might vanish if immigrant-origin students experience higher dropout rates in more demanding tracks (Dollmann and Weißmann, 2019; Tjaden and Hunkler, 2017). Moreover, dropout is associated with poor labour market outcomes and psychological distress (Bradley and Lenton, 2007; Liem et al., 2010).

Assessing the benefits of the educational choices of the children of immigrants requires further research. First, there is a need for greater clarity about the profile of immigrant-origin students who make ambitious educational choices relative to similar native students. Most studies compare the educational decisions of immigrant-origin and native students accounting for prior performance and parental occupational class. Results are reported as the average effects of having a immigrant background across the range of the two controlling variables, which makes it hard to infer whether they are entirely driven by certain groups of students. If the gaps are mostly due to the ambitious educational choices of very disadvantaged immigrant-origin students (lower class and low-performing), then the risk of subsequent dropout for immigrant-origin students and and the need for more support may be greater (Kilpi-Jakonen, 2011; Tjaden and Hunkler, 2017).

Second, most of the research focuses on a single educational transition, overlooking the ultimate outcomes of educational choices. There is evidence that the relatively ambitious educational choices of immigrant-origin students after compulsory education may lead to lower grades and a greater likelihood of dropout after the transition (Birkelund, 2020). Disadvantages in terms of completion rate can completely offset the positive effects of their ambitious choices (Dollmann and Weißmann, 2019). If the relatively ambitious educational choices of immigrant-origin students mostly lead to subsequent dropout, then we might be overstating their importance for migrant integration and social mobility. However, studies on their long-term consequences are limited. 
Third, researchers' focus on educational choices might overshadow the importance of the disadvantage of immigrant-origin students in terms of prior academic achievement. Ambitious educational decisions may lead to the narrowing of immigrant-native gaps ${ }^{1}$ in enrolment, but if immigrant-origin students' disadvantages in prior academic achievement are too large to be bridged, immigrant-native gaps in attainment will not be narrowed significantly (Birkelund, 2020; Dollmann and Weißmann, 2019). Comparing the consequences of the advantage of immigrant-origin students in terms of educational choices to the consequences of their disadvantages in terms of prior academic achievement can guide policies to close immigrant-native gaps in educational attainment (Dollmann, 2017).

In this article, I analyse immigrant-native gaps in the decision to enrol in academicallyoriented upper secondary education after the end of compulsory schooling and in later outcomes after the transition. I use panel data from the 1995 and 2007 cohorts of the Panel d'Élèves du Second Degré and I focus on the children of immigrants from North Africa, Turkey, and other African countries, the largest groups of non-European immigrants in France (INSEE, 2020). In my analyses,(i) I investigate how immigrant-native gaps in enrolment decisions vary by social class and previous academic achievement; (ii) I measure long-term immigrant-native gaps in educational outcomes (grade repetition, further educational choices and track completion) after the transition to academicallyoriented upper secondary education; (iii) I use counterfactual reweighting to investigate how early immigrant-native gaps in academic achievement in compulsory education and in enrolment decisions contribute to long-term disadvantages in educational outcomes after the transition for immigrant-origin students.

Regarding students' decisions for the transition, results confirm that immigrantorigin students were more likely to opt for the academically-oriented upper secondary track after accounting for prior achievement and social status. However, I also find that the immigrant-native gap was mostly driven by low-performing lower-class students, i.e. the most disadvantaged students. In terms of subsequent outcomes in upper secondary education, I find that immigrant-origin students were more likely not to continue in the academic track after the first year of upper secondary education, to be retained and to dropout. Using counterfactual reweighting, I show that between thirty and forty percent of these gaps were explained by immigrant-origin students' ambitious choices, depending on the outcome and the weights used. A similar share of the gaps can be explained by the lower academic performance of immigrant-origin students in lower secondary education.

This paper makes three potential contributions to the literature on ethnic inequalities in education. First, I demonstrate the importance of considering interactions between immigrant background, social class and previous academic performance when measuring immigrant-native gaps in enrolment decisions, in order to better identify ambitious immigrant-origin students. Second, I provide novel evidence on immigrant-native gaps in long-term educational outcomes beyond a single educational transition in France. Third, I show that early immigrant-native gaps in academic achievement and gaps in enrolment decisions have long-term impacts on later educational outcomes. 


\section{Theoretical Framework}

\section{Ethnic Choice Effects}

immigrant-native differences in educational choices are typically analyzed using the primary and secondary effects model (Boudon, 1974; Fernández-Reino, 2016; Jackson et al., 2012). The primary effects of ethnicity are usually defined as immigrant-native gaps in academic performance after accounting for socio-economic status (Fernández-Reino, 2016). Like the primary effects of social class, these tend to be negative, since immigrantorigin students usually underperfom academically compared to native students in compulsory education (Jackson et al., 2012; Jonsson and Rudolphi, 2011). The secondary effects of ethnicity - also called "ethnic choice effects" - are differences in educational continuation choices between immigrant-origin and native students after accounting for social class and prior academic performance. In contrast to the secondary effects of low social class, they are often positive, since immigrant-origin students from certain minority groups tend enrol in more demanding academic tracks compared to their native peers (Brinbaum and Cebolla-Boado, 2007; Fernández-Reino, 2016; Jackson et al., 2012).

According to the theory of blocked opportunities, second generation immigrants might expect discrimination in the labour market, which they might compensate for through academic titles (Heath and Brinbaum, 2007). Therefore, they likely associate higher benefits (or lower costs) to choosing more academically driven tracks (Dollmann, 2017; Heath and Brinbaum, 2007). According to the theory of lack of information, immigrant parents might lack information on the educational system since they may have been educated in their country of origin or may face linguistic barriers (Kao and Tienda, 1998). They might be especially unfamiliar with vocational and educational training (VET) options and their potential benefits (Tjaden and Hunkler, 2017). As a result, they could overestimate returns to more academically-oriented educational tracks and their likelihood of completing them.

According to theories of immigrant optimism, immigrants are a positively selected in terms of observable or unobservable characteristics that boost their aspirations for their children (Kao and Tienda, 1995). Immigrants tend to be positively selected in terms of educational attainment compared to the population in their country of origin, which may boost their subjective social status (Ichou, 2014; van de Werfhorst and Heath, 2019). They could also be selected in terms of motivation, risk-taking and other noncognitive skills (Polavieja et al., 2018). Pervasive optimism could also be inherently part of immigrants' identity assertion (Cebolla-Boado et al., 2021). All of these factors create family environments that stimulate the formation of high aspirations for the children of immigrants. Theories of immigrant optimism have found the greatest support in studies comparing alternative explanations of positive ethnic choice effects (Cebolla-Boado et al., 2021; Salikutluk, 2016; Fernández-Reino, 2016). 


\section{Heterogeneous Ethnic Choice Effects}

Although positive ethnic choice effects are a robust finding (see Brinbaum (2019) for France for example), few studies investigate how immigrant-native gaps in educational choices differ across specific groups of students. Specifically, ethnic choice effects may vary according to the social class and prior academic performance of students being compared. In other words, when measuring immigrant-native gaps in educational choices most studies assume simple additive effects of social class and prior performance, while interactions with students' immigrant background might be revealing. Immigrants-native differences may arise because minority students respond differently to their lower socioeconomic background and academic performance (Gil-Hernández and Gracia, 2018).

There is evidence that, in the transition to upper secondary education in Germany, positive ethnic choice effects are only concentrated among low-SES students (Dollmann, 2017). This is because the educational choices of native students are highly stratified by social class, while students with an immigrant background tend to have high educational aspirations regardless of their social background, due to of their desire for upward mobility despite all disadvantages (Salikutluk, 2016; Gil-Hernández and Gracia, 2018). These results raise some concerns about the sustainability of these educational decisions in Germany (Dollmann, 2017), but they have not been replicated in other educational systems. Moreover, interactions with prior academic performance have not been assessed.

There is ample evidence that enrolment decisions of upper-class students are less sensitive to educational signals than those of students from the working class (Bernardi, 2014; Holm et al., 2019). This can be explained by upper-class motivation and resources to avoid social demotion (Breen and Goldthorpe, 1997). Attempts to investigate the relationship between the educational choices of minority students and their prior academic achievement have been less systematic. There is some evidence that ethnic choce effects are larger when comparing students with relatively low levels of previous academic achievement (Birkelund, 2020; Kilpi-Jakonen, 2011). However, there has been limited effort to investigate how the achievement gradient in ethnic choice effects may also vary by social class (Kilpi-Jakonen, 2011).

In this paper, I analyze three-way interactions between immigrant background, parental social class, and previous academic performance in the decision to enrol in academic upper secondary education. I hypothesize that the desire of more advantaged native families to avoid social demotion irrespective of their children's academic ability is comparable to the desire of disadvantaged immigrant families for upward mobility despite all disadvantages (Bernardi, 2014; Breen and Goldthorpe, 1997; Salikutluk, 2016). Immigrant-native gaps should be small or null when comparing immigrant-origin and native students from the upper and intermediate classes. However, while the educational decisions of lower class native students are strongly dependent on their previous academic performance, those of lower-class immigrant-origin students are less sensitive to performance because of imigrant optimism (Gil-Hernández and Gracia, 2018). As a result, I hypothesize that the largest immigrant-native gaps in the decision to enrol in academic 
upper secondary are recorded when comparing immigrant-origin and native students from the lower class and with low previous academic achievement.

\section{Attainment After Ambitious Transitions}

Positive ethnic choice effects are applauded in the literature, because they are expected to contribute to closing immigrant-native gaps in educational attainment (Jackson et al., 2012). However, positive ethnic choice effects are usually recorded only after accounting for immigrant-origin students' disadvantage in terms of social class and school grades (indeed, choice effects may only be positive for the most disadvantaged students, as outlined in the previous section). Therefore, immigrant-origin students enroled in more prestigious tracks will start out more disadvantaged than native students, and will face greater risks of unfavorable academic outcomes such as grade repetition or dropout (Jonsson et al., 2014).

Immigrant-origin students who made optimistic enrolment decisions may compensate for their initial disadvantage over time and successfully fulfil their ambitions. However, there is ample evidence that immigrant-origin students have higher dropout rates in academic upper secondary education as a result of their social background and lower academic performance (Kalmijn and Kraaykamp, 2003; Storen and Helland, 2010). This points to the importance of exploring the long-term impact of positive ethnic choice effects and of early gaps in academic achievement on immigrant-native disadvantages in outcomes after the first educational transition.

There have been some attempts to measure the consequences of positive ethnic choice effects. In the German context, Dollmann and Weißmann (2019) show that migrant students' ambitious choices reduce immigrant-native gaps in academic upper secondary enrolment, but this effect is contrasted by a greater likelihood of dropout. Birkelund (2020) investigates immigrant-native inequalities in outcomes after the transition to academic upper secondary education in Denmark, and uses a counterfactual reweighting strategy to tease out the portion of those inequalities attributable to differences in enrolment decisions between immigrant-origin and native students. He shows that positive ethnic choice effects reduce immigrant-origin disadvantages in the attainment of upper secondary education but at the cost of greater dropout and lower grades for immigrant-origin students enroled in upper secondary education.

In my empirical analyses, I apply Birkelund's strategy to measure the impact of positive ethnic choice effects on educational outcomes after the transition and I expand on it by accounting for three-way interactions between immigrant background, social class, and prior academic achievement. Moreover, I run additional counterfactual analyses. Birkelund's strategy aims to measure the long-term consequences of immigrant-native differences in educational choices, while keeping their previous performance constant. In my second counterfactual analysis, I do the opposite: I estimate the long-term consequences of immigrant-native gaps in previous academic performance, while keeping their educational choices fixed. The reweighting approaches are further described in the meth- 
ods section.

\section{Secondary education in France}

Secondary education in France is divided into two cycles: the collège (lower secondary education) and the lycée (upper secondary education) (see Figure 1). The collège is a comprehensive school attended by all pupils. It starts in grade 6 (at the age of 11-12) and terminates in grade 3 with a general examination (brevet). The final brevet mark is a combination of class grades and performance in the national examination.

The last year of collège marks the end of compulsory education and students have the option of entering general and technological or vocational tracks. Students in the general and technological track (henceforth "GT track") pursue an academic or a technological certificate called baccalauréat, which grants access to university. Students in the vocational track pursue vocational certificates (the BEP - brevet d'études professionelles - or the CAP - certificat d'aptittude professionelle), after which they either enter the labor market or pursue a professional baccalauréat. Most students progress to one of these tracks and dropout after compulsory education is rare, although grade repetition in primary and lower secondary education is diffused.

Selection into upper secondary tracks occurs by means of a procedure called orientation at the end of the third grade. It is a months long negotiation between the family of the student and the Class Council, comprised of school principals, teachers and other educational experts. Families express track preferences that must be confirmed by the Council and decisions are mainly based on students' class grade component of the brevet score (since the actual exam is taken later). Council decisions can be appealed, in which case the final choice is made by an appeal committee. The system can be described as a "conservative choice-based" one, since families are allowed to choose and are most often granted their wish, but they are constrained by the Class Council.

After the first year of the GT upper secondary track (i.e. the second grade), families go through a second transition into either the general or technological track (see Figure 1). The former is more prestigious and favors access to elite and highly competitive universities, although also the technological track allows entrance into tertiary education (Brinbaum, 2019; Brinbaum and Cebolla-Boado, 2007). The second transition is decided through an orientation procedure identical to the first. In this paper, I study ethnic choice effects in the transition to GT upper secondary track after compulsory education (that is, the first transition). Among those enroled in the GT track, I explore immigrant-native gaps in outcomes after the first transition, such as decisions for the second transition, grade repetition and track completion.

Studying the French context represents an interesting addition to previous research on the consequences of positive ethnic choice effects in Denmark and Germany (Dollmann and Weißmann, 2019; Birkelund, 2020). The French educational system relies mostly on general education unlike the German and the Dutch ones where vocational training and 
apprenticeships are more common (Buchmann and Kriesi, 2011). Therefore, students face different incentives when making educational decisions that may be consequential for for ethnic choice effects (Tjaden and Hunkler, 2017). France has a choice-based system where enrolment decisions are heavily influenced by academic performance, which significantly influences immigrant-native gaps in enrolment and attainment (Jackson et al., 2012). Moreover, the second educational transition into the academic or technological track is a unique feature of the French system that may create further ethnic disparities and is worth investigating.

Figure 1: Structure of the French educational system

\begin{tabular}{|c|c|c|c|c|c|}
\hline Age & Grade & \multicolumn{3}{|c|}{ Track } & Transitions \\
\hline 18 & Terminal & \multirow{2}{*}{ Generale } & \multirow{2}{*}{ Technologique } & \multirow{3}{*}{ Vocational } & \\
\hline 17 & 1 & & & & \\
\hline $16-17$ & 2 & \multicolumn{2}{|c|}{ Generale $\&$ Technologique } & & Orientation procedure 2 (GT track only) \\
\hline $15-16$ & 3 & \multirow{4}{*}{\multicolumn{3}{|c|}{ Lower secondary education (College) }} & Orientation procedure 1 \\
\hline 14 & 4 & & & & \\
\hline 13 & 5 & & & & \\
\hline $11-12$ & 6 & & & & \\
\hline $10-11$ & CM 2 & \multirow{5}{*}{\multicolumn{3}{|c|}{ Primary education (École primaire) }} & \\
\hline 10 & CM 1 & & & & \\
\hline 9 & $\mathrm{CE} 2$ & & & & \\
\hline 8 & CE 1 & & & & \\
\hline $6-7$ & $\mathrm{CP}$ & & & & \\
\hline
\end{tabular}

\section{Data and Methods}

\section{Data}

The data I use come from the Panel d'élèves du second degré, a longitudinal study of students entering lower secondary education gathered by the French Ministry of Education (DEPP, 2008, 2015). The panel is obtained through yearly updates of administrative data combined with some additional cognitive assessments and family questionnaires. It includes rich data on students' performance in secondary education, on the two orientation procedures, and on their progress in upper secondary education.

I use the two most recent rounds of the survey, which cover cohorts of students entering lower secondary education for the first time in 1995 and 2007 respectively. I analyze both because each offers distinct advantages. While the most recent round has a larger sample size that allows for more statistical power in analyses, it does not yet include information on students' completion of upper secondary education, unlike the older round of the survey. I keep data from the two rounds of the survey separate because of the large time window that separates them, some minor changes that have occurred in the educational system, and of small differences in student samples composition. By running analyses separately for each round I can test the robustness of my results to these changes. 
In round of 1995, the sampling frame was composed only of students in Metropolitan France and a total of 17,830 students were sampled (DEPP, 2008). In the round of 2007, a sample of 34,986 students in Metropolitan France and Overseas Departments was drawn (DEPP, 2015). To ensure comparability across the two cohorts, I excluded students who were sampled from Overseas departments in the 2007 cohort, and students in the two cohorts that attended school in any of the Overseas Departments at any point in time. In 1995, the French educational system was more stratified, with a technological track already available in lower secondary education, although enrolment was relatively low (about $3 \%$ of the sample). To ensure comparability across the two cohorts, I excluded students who were enroled in this track in 1995.

In my analytical sample, I excluded foreign-born students because their sample sizes did not guarantee enough power for my empirical analyses and for meaningful comparisons with second-generation immigrant students. I excluded students with parents of mixed French-foreign origin because their educational choices resemble those of native students (Brinbaum and Cebolla-Boado, 2007). Among immigrant-origin students, I excluded students with parents from countries that were not identified in both surveys. Based on the results of some preliminary analyses, I excluded the children of European parents because they had more advantaged socio-economic backgrounds and the children of South East Asian parents because they had higher levels of academic achievement. Their sample sizes were not large enough to have distinct groups in my analyses. The remaining sample of immigrant-origin students is composed of the children of immigrants from North African countries, Turkey, and Other African countries ${ }^{2}$, the largest groups of non-European immigrants in France according to the latest census (INSEE, 2020).

Student background variables such as parental occupational class and country of origin were gathered using dedicated parental questionnaires administered one year after the beginning of the panels. I exclude students whose parents did not respond to the questionnaire. The response rate was high (85\% in 1995 and $93 \%$ in 2007 for non-repeaters) and missing answers are addressed through dedicated weights provided in the dataset (DEPP, 2008, 2015). Data on students' school grades in the last year of lower secondary education (i.e. the class grade component of the final examination of lower secondary education) were obtained from administrative records ${ }^{3}$. Information on students educational status and track enrolment was updated yearly through through administrative records or, in case of missing data, by contacting school principals and families. These methods ensure a relatively low attrition that is addressed through dedicated weights.

Grade repetition in lower secondary education was high, especially for the cohort of 1995 (Pirus, 2013). In order to maintain high power in the analyses and to provide representative estimates for the widest possible range of students, I keep students students who repeated at most one grade in lower secondary education (so that time-varying factors are measured with one year delay for them, as explained in greater detail below $)^{4}$. I exclude students who dropout immediately after the end of lower secondary education, since this group was very small in my sample (less than $1 \%$ ). 
The final analytical sample for the first part of the analyses investigating the transition to upper secondary education is composed of 8,476 students for the 1995 round and 20,966 students in the 2007 round of the survey. For the the second part of the analyses, the sample is restricted to students who were enroled in the GT track after compulsory education (13,437 in the round of 2007 and 5,832 in the round of 1995).

\section{Measures}

For the first part on the heterogeneity of ethnic choice effects, the outcome variable is a binary indicator of whether, in the first transition after compulsory education, students enroled in the GT track (as opposed enrolling in a vocational track or repeating the last year of compulsory schooling ${ }^{5}$ ). For the second part, on outcomes after the first transition, among students who enroled in the GT track after compulsory education, I define an indicator for: (1) whether they repeated the first year of upper secondary education (2) whether in the second transition they enroled in the general track (as opposed to the technological or vocational track or they repeated the first year of upper secondary education). For students who repeated one year in lower secondary education, I define outcomes using their tracked educational status one year later compared to nonrepeaters. In the round of 1995, I also investigate track completion, defined as whether students completed the general or the technological upper secondary tracks up to two years after the modal time ${ }^{6}$.

The main independent variable is students' immigrant background, which was defined based on parental country of birth reported in the family questionnaire. I define French students as having two French-born parents. Immigrant-origin students were those with foreign-born parents from either North Africa, Turkey, or other African countries. In line with previous research, when parents came from different foreign countries, I assigned the one of the mother as the country of origin.

I measure social origin using parental occupational class coded using a three-fold scheme composed of the upper class (professionals, managers and higher-level technicians), the intermediate class (self-employed workers and routine non-manual workers) and the working class (skilled and unskilled manual workers along with farmers). Values were assigned using the dominance criterion. I opt for parental occupational class rather than educational attainment because educational titles are not easily transferable from migrants' countries of origin and may be misclassified, and because occupational class is more representative of immigrants' current situation because of occupational downgrading.

Prior academic achievement is defined using the class grade component of the national examination at the end of lower secondary education, which is the information used by parents and schools for enrolment decisions. I take the average of class grades in French and mathematics, which are the most important for enrolment decisions (Brinbaum and Cebolla-Boado, 2007), and compute quintiles of performance. For students who repeated one year in lower secondary education, so who reached the educational 
transition one year later compared to non-repeaters, I use information on their academic achievement in the year of the enrolment decision ${ }^{7}$.

Table A1 describes the analytical samples. In both cohorts and especially in 1995, immigrant-origin students were more likely to have a disadvantaged social background. They were also more likely to have repeated a grade in lower secondary education and to be in the lowest quintile of school grades in lower secondary education. In both cohorts, immigrant-origin students were less likely to enrol in the GT track after compulsory education without controlling for background characteristics.

Table 1: Descriptive statistics

\begin{tabular}{|c|c|c|c|c|}
\hline & \multicolumn{2}{|c|}{2007} & \multicolumn{2}{|c|}{1995} \\
\hline & $\begin{array}{c}\text { Native } \\
(\mathrm{N}=18,977)\end{array}$ & $\begin{array}{c}\text { Immigrant } \\
\text { origin } \\
(\mathrm{N}=1,989)\end{array}$ & $\begin{array}{c}\text { Native } \\
(\mathrm{N}=7,861)\end{array}$ & $\begin{array}{c}\text { Immigrant } \\
\text { origin } \\
(\mathrm{N}=615)\end{array}$ \\
\hline & $\%$ & $\%$ & $\%$ & $\%$ \\
\hline \multicolumn{5}{|l|}{ Origin } \\
\hline France & 100.0 & 0.0 & 100.0 & 0.0 \\
\hline North Africa & 0.0 & 67.7 & 0.0 & 79.7 \\
\hline Turkey & 0.0 & 10.4 & 0.0 & 7.2 \\
\hline Other African country & 0.0 & 21.9 & 0.0 & 13.1 \\
\hline \multicolumn{5}{|l|}{ Parental occupational class } \\
\hline Upper & 25.6 & 13.1 & 21.3 & 5.3 \\
\hline Intermediate & 65.3 & 58.2 & 64.1 & 38.0 \\
\hline Working & 9.1 & 28.6 & 14.6 & 56.7 \\
\hline \multicolumn{5}{|l|}{ Grade repetition in lower secondary } \\
\hline Never repeated & 89.8 & 87.0 & 75.0 & 64.6 \\
\hline Repeated once & 10.2 & 13.0 & 25.0 & 35.4 \\
\hline \multicolumn{5}{|c|}{ Quintiles of grades in lower secondary } \\
\hline Bottom & 17.6 & 33.8 & 19.7 & 42.7 \\
\hline 2nd & 19.9 & 21.1 & 20.0 & 19.9 \\
\hline $3 \mathrm{rd}$ & 21.1 & 18.4 & 22.5 & 16.0 \\
\hline 4 th & 21.0 & 13.8 & 17.7 & 11.7 \\
\hline Top & 20.3 & 12.9 & 20.0 & 9.6 \\
\hline \multicolumn{5}{|c|}{ Enrollment after compulsory education } \\
\hline Vocational track or grade repetition & 32.2 & 37.8 & 31.6 & 42.8 \\
\hline General and Technological (GT) track & 67.8 & 62.2 & 68.4 & 57.2 \\
\hline
\end{tabular}

Source: Panel d'élèves du second degré 2007 and 1995 cohorts, own calculations.

\section{Methods}

In the first part of the analysis, on heterogeneous ethnic choice effects, I run two sets of models. In the first, I estimate standard ethnic choice effects: I fit logistic regressions to estimate immigrant-native gaps in the likelihood of enrolling in the GT track after compulsory education, accounting for students' prior academic achievement and parental occupational class. I present results both aggregated for immigrant-origin students and separated by country of origin. In the second step, I explore heterogeneity in immigrant-native gaps by adding two-way and three-way interactions between students' 
immigrant background, parental occupational class, and prior academic performance. To have enough power for interactions, I contrast native students with the entire group of children of immigrants.

I carry out analyses without additional control variables to adopt the standard definition of ethnic choice effects in the literature (Fernández-Reino 2016) and avoid overcontrolling for possible mediators. However, my results are robust to the inclusion of additional control variables, including: students' gender, number of siblings, whether they lived with both of their parents, a measure of parental education and indicators for whether students repeated a grade in lower secondary or primary education. Appendix A provides descriptive statistics for additional control variables and compares repeaters and non-repeaters, while Appendix B and Appendix C present results from analyses with additional controls and from analyses that were run separately for repeaters and non-repeaters.

For the second part of the analysis, I focus on students enroled in the GT track after compulsory education and I analyze gaps between native and immigrant-origin students in the outcomes after the first transition. First, I measure simple gaps using simple logistic regressions. Then, I investigate the extent to which those gaps are explained by the performance of immigrant-origin students in lower secondary education and their educational choices by asking the following three counterfactual questions:

1. How would immigrant-origin students perform after the transition to the GT upper secondary track if they had the same grades as native students at the end of compulsory education (keeping their educational choices constant)?

2. How would immigrant-origin students perform after the transition to the GT upper secondary track if they made the same performance-specific educational choices as native students (keeping their grades at the end of compulsory education constant)?

3. How would immigrant-origin students perform after the transition to the GT upper secondary track if they made the same performance-specific and class-specific educational choices as native students (keeping their grades at the end of compulsory education constant)?

Previous research has attempted to disentangle the primary and secondary effects of social class by generating simulated counterfactual scenarios (Bernardi and Triventi, 2018; Erikson et al., 2005). To answer the questions above, I apply counterfactual reweighting strategies used in standardization by demographers and for decomposition by economists (Fortin et al., 2011; Gupta, 1994; Hernán and Robins, 2020). For the first question, I compute the likelihood for immigrant-origin and native students of having lower secondary grades in each quintile of the performance distribution by fitting a multinomial logistic regression controlling for parental social class and obtaining predicted probabilities. For each quintile of previous performance $i$, I define a weight $w_{i}$ that is the ratio of the 
probability of native students being in that quintile to the probability for immigrantorigin students. I assign weights to immigrant-origin students, while native students are assigned a weight of 1 .

Applying weights make the distribution of previous academic achievement of immigrantorigin and native students identical, while keeping their educational choices unchanged. This isolates the part of the mediating effect of previous performance that is due to compositional differences between the two groups, and is known as direct standardization in the standardization literature (Gupta, 1994). By answering counterfactual question 1), I attempt to measure the impact of the primary effects of ethnicity on immigrant-native gaps after the transition. For this reason, I call these weights "primary weights".

To answer the second question, I replicate the reweighting strategy used by Birkelund (2020). I fit a logistic model regressing the likelihood of enrolling in the GT second grade on social class, quintiles of previous grades, immigrant status, and the interaction of the latter two. I compute performance-specific probabilities of enrolling in the GT track for immigrant-origin and native students. For each quintile of academic performance $i$, I define a weight $w_{i}$ that is the ratio of the probability for native students in quintile $i$ of enrolling in the GT track to the probability for immigrant-origin students in the same quintile of enrolling in the GT track. I assign the weights to immigrant-origin students, while native students are assigned a weight of 1 .

Applying these weights makes the performance-specific enrolment decisions of immigrantorigin and native students identical, while keeping their previous academic achievement unchanged. This is known as indirect standardization in the standardization literature (Gupta, 1994). These weights correspond conceptually to the definition of secondary effects of ethnicity in the literature, and I label them "Secondary weights".

The third counterfactual question stems from previous considerations on the importance of interactions between parental class and previous grades for estimating ethnic choice effects. To answer it, I expand on the work of Birkelund (2020). I fit a logistic model regressing the likelihood of enrolling in the GT second grade on social class, quintiles of previous grades, immigrant status, and interactions of the three. I compute performance- and class-specific probabilities of enrolling in the GT track for immigrantorigin and native students. For each quintile of academic performance performance $i$ and parental class $j$, I define a weight $w_{i j}$ that is the ratio of the probability for native students in quintile $i$ and with parental class $j$ of enrolling in the GT track to the probability for immigrant-origin students with the same social class and previous academic performance. I assign weights to immigrant-origin students, while native students are assigned a weight of 1 . Some of these weights were not estimateable because of small sample sizes in threeway interactions, so I assign students in these cells a weight of $1^{8}$. I label the third set of weights "triple interaction weights".

Appendix D presents the weights used for each survey round, discusses some of the issues associated with using point estimates of predicted probabilities to compute weights, and presents results from robustness analyses based on the idea of bounds. 


\section{Results}

\section{Enrolment in upper secondary education and heterogeneous ethnic choice effects}

In this section, I present different estimates of ethnic choice effects in the transition to the GT track after compulsory education. Tables 2 and 3 present estimates of simple ethnic choice effects, as defined in the literature, for the 2007 and 1995 cohorts of the Panel d'élèves du second degré. I first show simple gaps (Model 1) and gradually add controls for parental occupational class (Model 2) and prior academic achievement (Model 3). After including all controls, immigrant-origin students were about 10 percentage points more likely to enrol in the GT track than native students in both cohorts. In the 2007 cohort, estimates for Turkish-origin students in Model 3 were similar to those of North African students. By contrast, in the cohort of 1995 they were as likely as native students to enrol in the GT track (but they were 27 percentage points less likely before including controls). Analyses in Appendix B shows that ethnic choice effects were more than double among students who repeated one grade in lower secondary education, with gaps in enrolment in the GT track as large as 20 percentage points after accounting for control variables. Appendix B shows that positive ethnic choice effects were even larger when including the full set of control variables.

Table 2: Average marginal effects from logistic models predicting enrolment in the general and technological track after compulsory education, 2007 cohort

\begin{tabular}{|c|c|c|c|c|c|c|}
\hline \multirow[b]{2}{*}{ Origin (reference: Native students } & \multicolumn{2}{|c|}{$\begin{array}{c}\text { Model } 1 \\
\text { (no controls) }\end{array}$} & \multicolumn{2}{|c|}{$\begin{array}{c}\text { Model } 2 \\
(+ \text { class Controls })\end{array}$} & \multicolumn{2}{|c|}{$\begin{array}{c}\text { Model } 3 \\
(+ \text { grades controls })\end{array}$} \\
\hline & & & & & & \\
\hline Immigrant-origin students & $\begin{array}{c}-0.057^{* * *} \\
(0.012)\end{array}$ & & $\begin{array}{c}0.018 \\
(0.011)\end{array}$ & & $\begin{array}{c}0.095^{* * *} \\
(0.007)\end{array}$ & \\
\hline \multicolumn{7}{|c|}{ Origin (reference: Native students) } \\
\hline North Africa & & $\begin{array}{l}-0.030^{*} \\
(0.014)\end{array}$ & & $\begin{array}{l}0.037^{* *} \\
(0.013)\end{array}$ & & $\begin{array}{l}0.104^{* * *} \\
(0.008)\end{array}$ \\
\hline Turkey & & $\begin{array}{c}-0.117^{* *} \\
(0.036)\end{array}$ & & $\begin{array}{c}0.043 \\
(0.029)\end{array}$ & & $\begin{array}{c}0.096^{* * *} \\
(0.019)\end{array}$ \\
\hline Other African country & & $\begin{array}{c}-0.111^{* * *} \\
(0.026)\end{array}$ & & $\begin{array}{l}-0.054^{*} \\
(0.023)\end{array}$ & & $\begin{array}{c}0.069^{* * *} \\
(0.015)\end{array}$ \\
\hline Observations & 20966 & 20966 & 20966 & 20966 & 20966 & 20966 \\
\hline Pseudo $\mathrm{R}^{2}$ & 0.001 & 0.001 & 0.085 & 0.085 & 0.370 & 0.370 \\
\hline
\end{tabular}

Notes: The table reports average marginal effects from logistic regressions with standard errors in parentheses. Model 1 presents gross gaps, model 2 controls for parental occupational class and model 3 controls for students' quintile of compulsory school grades before making the transition.

* $p<0.05, * * p<0.01, * * * p<0.001$.

Source: Panel d'élèves du second degré 2007 cohort, own calculations. 
Table 3: Average marginal effects from logistic models predicting enrolment in the general and technological track after compulsory education, 1995 cohort

\begin{tabular}{|c|c|c|c|c|c|c|}
\hline \multirow[b]{2}{*}{ Origin (reference: Native students) } & \multicolumn{2}{|c|}{$\begin{array}{c}\text { Model 1 } \\
\text { (no controls) }\end{array}$} & \multicolumn{2}{|c|}{$\begin{array}{c}\text { Model } 2 \\
(+ \text { class Controls) } \\
\end{array}$} & \multicolumn{2}{|c|}{$\begin{array}{c}\text { Model } 3 \\
(+ \text { grades controls }) \\
\end{array}$} \\
\hline & & & & & & \\
\hline Immigrant-origin students & $\begin{array}{c}-0.112^{* * *} \\
(0.021)\end{array}$ & & $\begin{array}{c}0.010 \\
(0.019)\end{array}$ & & $\begin{array}{c}0.104^{* * *} \\
(0.012)\end{array}$ & \\
\hline \multicolumn{7}{|c|}{ Origin (reference: Native students) } \\
\hline North Africa & & $\begin{array}{c}-0.102^{* * *} \\
(0.023)\end{array}$ & & $\begin{array}{c}0.025 \\
(0.020)\end{array}$ & & $\begin{array}{c}0.111^{* * *} \\
(0.013)\end{array}$ \\
\hline Turkey & & $\begin{array}{c}-0.270^{* * *} \\
(0.074)\end{array}$ & & $\begin{array}{c}-0.088 \\
(0.071)\end{array}$ & & $\begin{array}{c}0.042 \\
(0.042)\end{array}$ \\
\hline Other African country & & $\begin{array}{l}-0.089 \\
(0.056)\end{array}$ & & $\begin{array}{l}-0.036 \\
(0.052)\end{array}$ & & $\begin{array}{l}0.089^{* *} \\
(0.032)\end{array}$ \\
\hline Observations & 8476 & 8476 & 8476 & 8476 & 8476 & 8476 \\
\hline Pseudo R ${ }^{2}$ & 0.003 & 0.004 & 0.074 & 0.075 & 0.385 & 0.385 \\
\hline
\end{tabular}

Notes: The table reports average marginal effects from logistic regressions with standard errors in parentheses. Model 1 presents gross gaps, model 2 controls for parental occupational class and model 3 controls for students' quintile of compulsory school grades before making the transition.

$* p<0.05,{ }^{* *} p<0.01, * * * p<0.001$.

Source: Panel d'élèves du second degré 1995 cohort, own calculations.

Figure 2 presents marginal probabilities from the same logistic regressions as in Model 3 of Tables 2 and 3 after including also two-way interactions ${ }^{9}$. The top two graphs show that ethnic choice effects are largest when comparing lower class immigrant-origin and native students. Ethnic choice effects were small or null among intermediate and upper class students. The lower two graphs show that ethnic choice effects were largest in the lowest part of the academic performance distribution, while at the top of the academic performance there were small or null differences in enrolment decisions between immigrant-origin and native students. These results are in line with previous findings in the literature (Birkelund, 2020; Dollmann, 2017) 
Figure 2: Predicted probabilities of enrolment in the general and technological track after compulsory education from logistic regressions with 2-way interactions between immigrant background and parental class, and 2-way interactions between immigrant background and quintiles of lower secondary grades
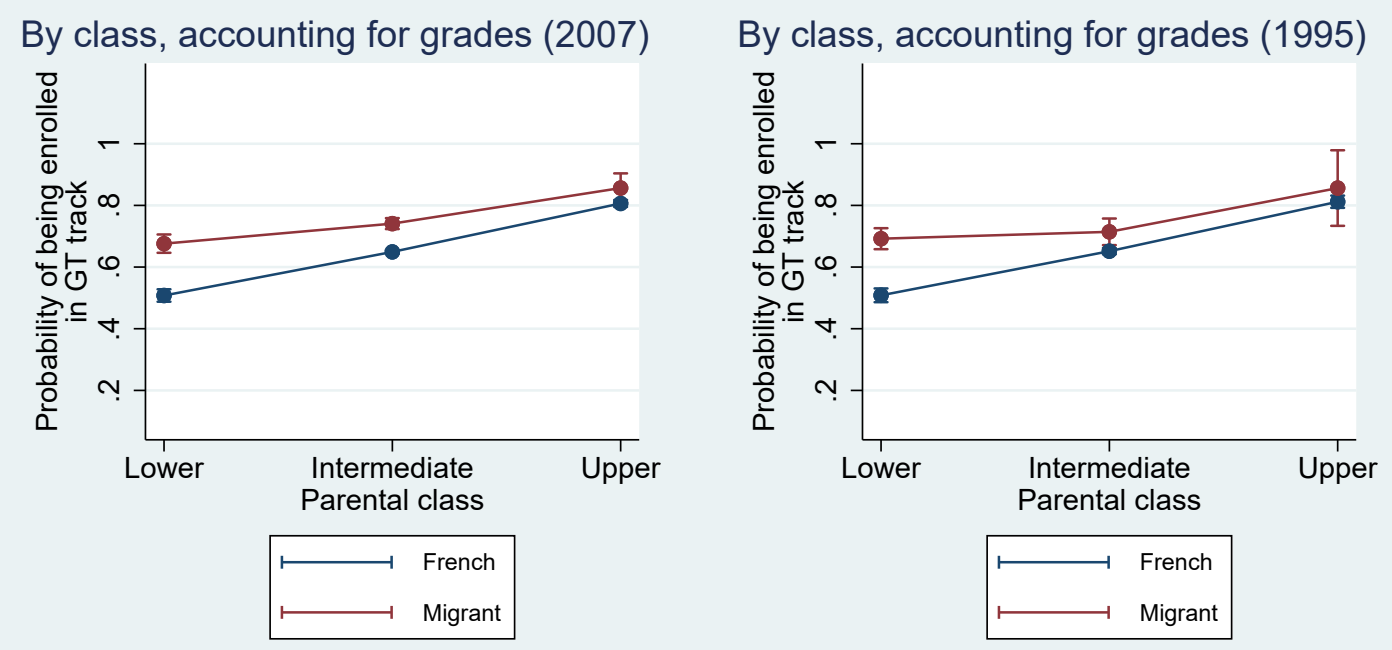

By grades, accounting for class (2007)
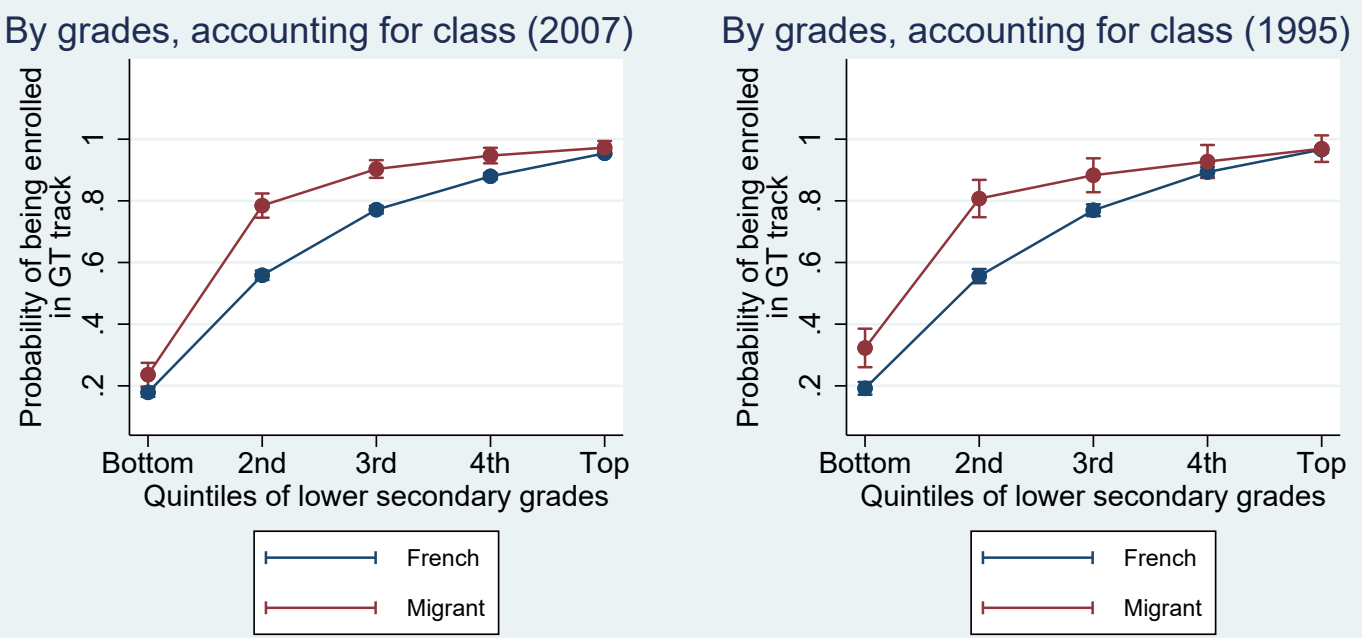

Notes: The top panel of the figure shows predicted probabilities from logistic models regressing of enrolment in the general and technological second grade on students' immigrant background interacted with parental occupational class and controlling for their grades in the last year of lower secondary education. The bottom panel of the figure shows predicted probabilities from logistic models regressing of enrolment in the general and technological second grade on students' immigrant background interacted with their grades in the last year of lower secondary education, accounting for parental occupational class. Estimates are presented with 95 percent confidence intervals.

Source: Panel d'élèves du second degré 2007 and 1995 cohorts, own calculations.

Figure 3 shows that including three-way interactions in the logistic models reveals further patterns in ethnic choice effects across social class and previous academic performance $^{10}$. The top left graph suggests that, in the 2007 cohort, among upper class students, there were no immigrant-native differences in the likelihood of enrolling in the GT track across the distribution of previous performance. However, probabilities were not estimateable or not precisely estimated due to small sample sizes, especially in the cohort of $1995^{11}$. The middle graphs show that, when comparing immigrant-origin and native students in the intermediate class, ethnic choice effects are mostly concentrated 
in the second quintile of academic performance. For example, in the 2007 cohort, among intermediate class students in the second quintile of compulsory school performance, immigrant-origin students were just over 20 percentage points more likely than native students to enrol in the GT track. However, the largest differences were recorded among lower class students in the second quintile of previous performance: in the 2007 cohort, among lower class students in the second quintile of compulsory school performance, immigrant-origin students were 35 percentage points more likely than native students to enrol in the GT track.

Figure 3 shows that ethnic choice effects were mainly the result of lower class lowperforming immigrant-origin students being more likely to enrol in the GT track than lower class low-performing native students. Results were similar between the two cohorts despite differences in immigrant-native gaps in social background and prior academic achievement across the two cohorts. Even though some results were not precisely estimated or not estimable, these mostly refer to the top quintiles of academic performance, where enrolment is almost universal (see Figure 2). Additional analyses presented in Appendix $\mathrm{C}$ show that results were robust to the inclusion of the full set of control variables, and were similar for repeaters and non-repeaters. 
Figure 3: Predicted probabilities of enrolment in the general and technological track after compulsory education from logistic regressions with 3-way interactions between immigrant background, parental class and and quintiles of lower secondary grades
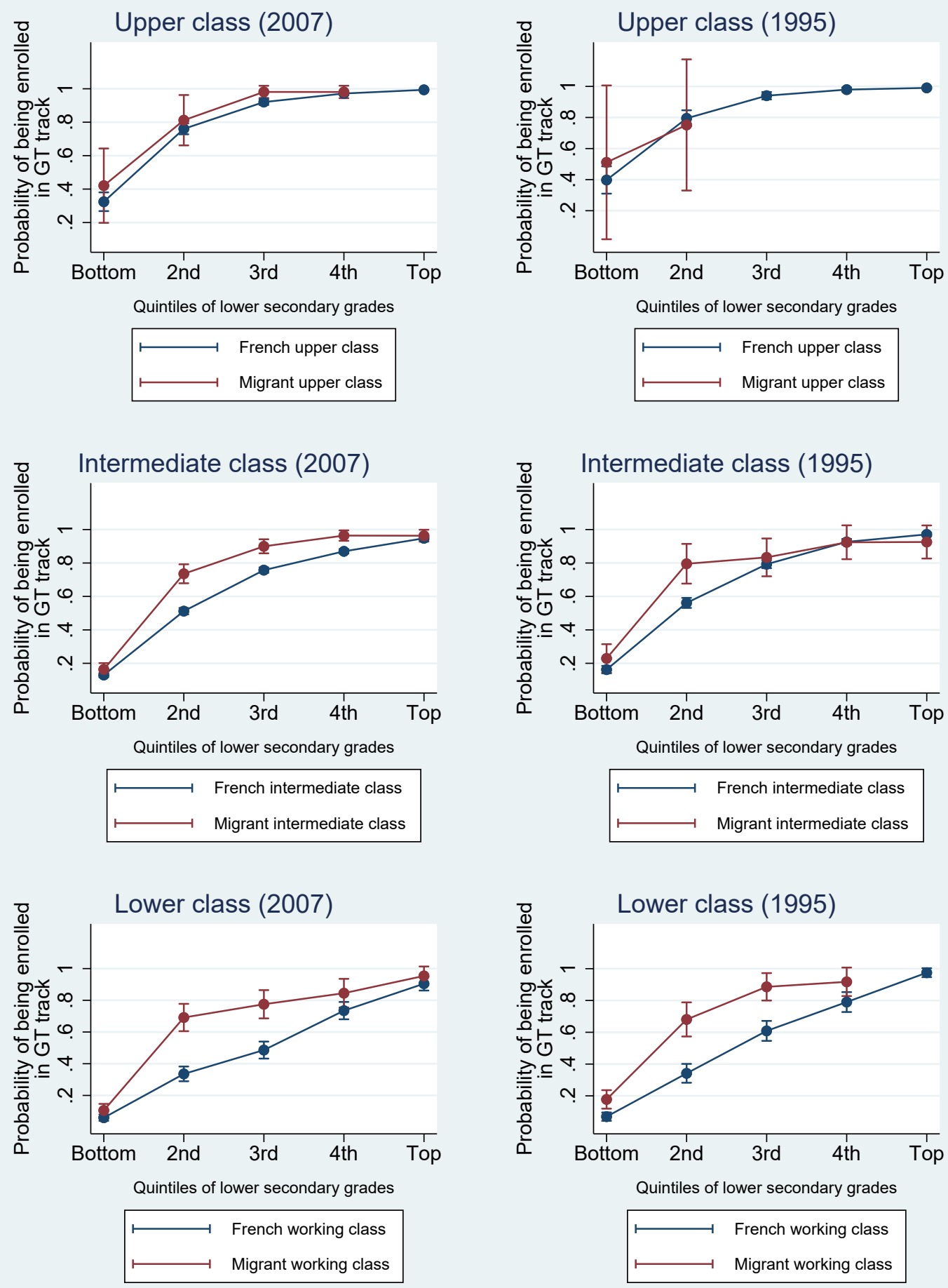

Notes: The figure shows predicted probabilities of enrolment in the general and technological second grade from logistic models including 3-way interactions of students' immigrant background, parental occupational class and quintiles of school grades in the last year of lower secondary education. Results are presented by comparing immigrant and native students in each social class and by quintiles of lower secondary grades. Estimates are presented with 95 percent confidence intervals.

Source: Panel d'élèves du second degré 2007 and 1995 cohorts, own calculations. 


\section{Outcomes in academic upper secondary education}

Table 4 and Table 5 analyze immigrant-native gaps in upper secondary outcomes in the two cohorts of the survey by fitting logistic models. Model 1 reports gross gaps in the outcomes considered, while models 2-4 compare the gap after applying the three sets of counterfactual weights. In model 5 , I expand on model 4 by adding controls for previous academic performance, which makes the performance distributions of the two groups overlap completely. In model 6 I additionally control for parental occupational class.

Panel A of Table 4 shows that immigrant-origin students were about six percentage points more likely than native students to repeat the first year of the GT upper secondary track in the 2007 cohort (Model 1). The gap was almost halved when primary weights were applied, while the other two weights reduced the gap by about 1.5 percentage points. Controlling for previous academic performance in Model 5 (i.e. making the performance distribution for immigrant-origin and native students identical) reduces the gap to less than two percentage points. Results for the 1995 cohort were less informative due to smaller sample sizes, but they suggest a stronger effect of interaction weights compared to the other two sets of weights (Table 5).

Panel B of Tables 4 and 5 show that immigrant-origin students were 10 and 20 percentage points less likely to enrol in the general track after the second transition in the cohorts of 2007 and 1995 respectively. Applying primary weights reduces this gap by almost half in the cohort of 2007 and by about one fourth in the cohort of 1995. In the cohort of 2007, the gap was reduced by one extra percentage point when applying triple interaction weights compared to secondary weights. Controlling for previous academic performance made the gap significantly smaller in both cohorts and statistically nonsignificant in the one of 2007.

Panel C of Table 5 shows that immigrant-origin students were about eight percentage points less likely to complete either the general or the technoogical track. The gap was reduced by 1 to 1.5 percentage points when weights were applied, while controlling for previous performance reduced the gap to a non-statistically significant amount. More specifically, immigrant-origin students were 20 percentage points less likely to complete the general track (Panel D). Comparing the estimate with Panel B suggests that this is mostly because they were unlikely to enrol in this track in the second transition. 
Table 4: Average marginal effects from logistic models predicting outcomes after the first transition into the general and technological upper secondary track, 2007 cohort

\begin{tabular}{|c|c|c|c|c|c|c|}
\hline & $(1)$ & $(2)$ & $(3)$ & $(4)$ & $(5)$ & $(6)$ \\
\hline & Gross & $\begin{array}{l}\text { Primary } \\
\text { weight }\end{array}$ & $\begin{array}{l}\text { Simple } \\
\text { secondary } \\
\text { weight }\end{array}$ & $\begin{array}{c}\text { Interaction } \\
\text { secondary } \\
\text { weight }\end{array}$ & $\begin{array}{c}+ \text { lowsec } \\
\text { grades }\end{array}$ & $\begin{array}{c}+ \\
\text { Class }\end{array}$ \\
\hline \multicolumn{7}{|c|}{ Panel A: Repeating the first year of GT upper secondary education } \\
\hline Immigrant-native gap & $\begin{array}{c}0.057^{* * *} \\
(0.011)\end{array}$ & $\begin{array}{c}0.034^{* * *} \\
(0.010)\end{array}$ & $\begin{array}{c}0.043^{* * *} \\
(0.010)\end{array}$ & $\begin{array}{c}0.041^{* * *} \\
(0.010)\end{array}$ & $\begin{array}{l}0.019^{*} \\
(0.008)\end{array}$ & $\begin{array}{l}0.021^{*} \\
(0.009)\end{array}$ \\
\hline Observations & 13437 & 13437 & 13437 & 13437 & 13437 & 13437 \\
\hline Pseudo - $\mathrm{R}^{2}$ & 0.005 & 0.003 & 0.003 & 0.003 & 0.171 & 0.171 \\
\hline \multicolumn{7}{|c|}{ Panel B: Enrollment in the general track in the second transition } \\
\hline Immigrant-native gap & $\begin{array}{c}-0.102^{* * *} \\
(0.016)\end{array}$ & $\begin{array}{c}-0.060^{* * *} \\
(0.016)\end{array}$ & $\begin{array}{c}-0.071^{* * *} \\
(0.016)\end{array}$ & $\begin{array}{c}-0.060^{* * *} \\
(0.016)\end{array}$ & $\begin{array}{c}-0.014 \\
(0.013)\end{array}$ & $\begin{array}{c}0.009 \\
(0.013)\end{array}$ \\
\hline Observations & 13437 & 13437 & 13437 & 13437 & 13437 & 13437 \\
\hline Pseudo - $\mathrm{R}^{2}$ & 0.005 & 0.004 & 0.004 & 0.003 & 0.225 & 0.244 \\
\hline
\end{tabular}

Notes: The table reports average marginal effects from logistic regressions with standard errors in parentheses. Model 1 controls for students' gender. Model 2 estimates Model 1 with primary counterfactual weights. Model 3 estimates Model 1 with simple secondary weights. Model 4 estimates Model 1 with triple interaction weights. Model 5 adds controls for students' quintile of compulsory school grades before making the transition to Model

4. Model 6 adds controls for parental occupational class to Model 5.

* $p<0.05,{ }^{* *} p<0.01,{ }^{* * *} p<0.001$.

Source: Panel d'élèves du second degré 2007 cohort, own calculations.

Table 5: Average marginal effects from logistic models predicting outcomes after the first transition into the general and technological upper secondary track, 1995 cohort

\begin{tabular}{|c|c|c|c|c|c|c|}
\hline & $(1)$ & $(2)$ & $(3)$ & $(4)$ & $(5)$ & $(6)$ \\
\hline & Gross & $\begin{array}{l}\text { Primary } \\
\text { weight }\end{array}$ & $\begin{array}{l}\text { Simple } \\
\text { secondary } \\
\text { weight }\end{array}$ & $\begin{array}{c}\text { Interaction } \\
\text { secondary } \\
\text { weight }\end{array}$ & $\begin{array}{c}+ \text { lowsec } \\
\text { grades }\end{array}$ & $\begin{array}{c}+ \\
\text { Class }\end{array}$ \\
\hline \multicolumn{7}{|c|}{ Panel A: Repeating the first year of GT upper secondary education } \\
\hline Immigrant-native gap & $\begin{array}{c}-0.077^{* * *} \\
(0.021)\end{array}$ & $\begin{array}{c}-0.053^{* *} \\
(0.020)\end{array}$ & $\begin{array}{c}-0.059^{* *} \\
(0.020)\end{array}$ & $\begin{array}{c}-0.055^{* *} \\
(0.020)\end{array}$ & $\begin{array}{l}-0.025 \\
(0.017)\end{array}$ & $\begin{array}{l}-0.003 \\
(0.017)\end{array}$ \\
\hline Observations & 5832 & 5832 & 5832 & 5832 & 5832 & 5832 \\
\hline Pseudo - $\mathrm{R}^{2}$ & 0.007 & 0.005 & 0.005 & 0.004 & 0.113 & 0.122 \\
\hline \multicolumn{7}{|c|}{ Panel B: Enrollment in the general track in the second transition } \\
\hline Immigrant-native gap & $\begin{array}{c}-0.208^{* * *} \\
(0.027)\end{array}$ & $\begin{array}{c}-0.164^{* * *} \\
(0.028)\end{array}$ & $\begin{array}{c}-0.171^{* * *} \\
(0.027)\end{array}$ & $\begin{array}{c}-0.148^{* * *} \\
(0.028)\end{array}$ & $\begin{array}{c}-0.090^{* * *} \\
(0.024)\end{array}$ & $\begin{array}{l}-0.024 \\
(0.024)\end{array}$ \\
\hline Observations & 5832 & 5832 & 5832 & 5832 & 5832 & 5832 \\
\hline Pseudo - $\mathrm{R}^{2}$ & 0.016 & 0.013 & 0.012 & 0.011 & 0.191 & 0.223 \\
\hline
\end{tabular}

Notes: The table reports average marginal effects from logistic regressions with standard errors in parentheses. Model 1 controls for students' gender. Model 2 estimates Model 1 with primary counterfactual weights. Model 3 estimates Model 1 with simple secondary weights. Model 4 estimates Model 1 with triple interaction weights. Model 5 adds controls for students' quintile of compulsory school grades before making the transition to Model 4. Model 6 adds controls for parental occupational class to Model 5.

${ }^{*} p<0.05,{ }^{* *} p<0.01,{ }^{* * *} p<0.001$.

Source: Panel d'élèves du second degré 1995 cohort, own calculations.

Results show that a significant portion of ethnic disadvantages in upper secondary education are driven by positive ethnic choice effects and the negative primary effects of ethnicity. Comparing the sizes of coefficients between Models 2-4 suggest that the strongest negative effects is the one of the primary effects of ethnicity ${ }^{12}$. This is further corroborated by the finding that many gaps disappear or are quantitatively small when the prior academic achievement of immigrant-origin and native students is equated in Model 5. Comparing Models 3 and 4 suggests that using triple interaction rather than secondary weights can provide different estimates of the consequences of ethnic choice 
effects on later outcomes.

Table 6 presents observed and counterfactual probabilities of enrolment in and completion of the general or technological track for immigrant-origin and native students. Comparing the first two panels shows that, in absolute terms, positive ethnic choice effects increase enrolment in the GT track (13 percentage points) and completion (9 percentage points) for immigrant-origin students, even though they increase their likelihood of dropout relative to native students (2.2 percentage points). Panel $\mathrm{C}$ shows that if immigrant-origin students had the same academic performance at the end of lower secondary education as native students, they would have higher enrolment rates than native students in the GT track and an 14 percentage point higher completion rate compared to their observed one.

Table 6: Observed and counterfactual GT upper secondary track enrolment and completion, 1995 cohort

\begin{tabular}{lccc}
\hline \hline & $\begin{array}{c}\text { GT enrollment } \\
(\%)\end{array}$ & $\begin{array}{c}\text { GT track } \\
\text { completion (\%) }\end{array}$ & $\begin{array}{c}\text { Completion among } \\
\text { enrolled (\%) }\end{array}$ \\
\hline Panel A: Observed outcomes & & & \\
Native students & 68.4 & 60.3 & 88.1 \\
Immigrant-origin students & 57.2 & 46.1 & 80.7 \\
\hline Panel B: Counterfactual & using triple interaction weights & 88.1 \\
Native students & 68.4 & 60.3 & 82.9 \\
Immigrant-origin students & 44.1 & 36.5 & \\
\hline Panel C: Counterfactual using primary weights & 88.4 \\
Native students & 68.4 & 60.3 & 83.2 \\
Immigrant-origin students & 73.6 & 61.2 & \\
\hline \hline
\end{tabular}

Notes: The table reports predicted probabilities from simple logistic models of outcomes regressed on an indicators for students' immigrant background applying different weights.

${ }^{*} p<0.05,{ }^{* *} p<0.01,{ }^{* * *} p<0.001$.

Source: Panel d'élèves du second degré 1995 cohort, own calculations.

\section{Discussion}

The ambitious educational choices of students with an immigrant background have gained considerable attention in research because of their potential to close immigrant-native gaps in educational attainment. However, recent research has produced evidence on some of the negative consequences of such ambitious enrolment decisions (Birkelund, 2020; Dollmann and Weißmann, 2019). This article contributes to this literature by providing a more nuanced account of positive ethnic choice effects in upper secondary enrolment decisions, and by measuring their long-term consequences on upper secondary education outcomes along with the consequences of early immigrant-native gaps in academic achievement.

I find that positive immigrant-native gaps in the enrolment to the more prestigious upper secondary track were substantial only when comparing low-performing students with a lower-class background. In other words, ethnic advantages in terms of educational choices were only recorded among most disadvantaged students. I also find that after the transition to the general and technological track, immigrant-origin students were, more likely to repeat a year, more likely to dropout, and less likely to continue to the general 
track and complete it. Using counterfactual reweighting I show that thirty to forty percent of these gaps were explained by the ambitious choices of immigrant-origin students and that a slightly higher share was attributable to lower prior achievement of immigrantorigin students in lower secondary-education. The estimated impacts of ethnic choice effects were slightly larger when triple interaction weights were used instead of secondary weights.

My results demonstrate the importance of considering interactions between ethnic origin, social class and academic performance when measuring the secondary effects of ethnicity. This gives greater clarity to the immigrant-native comparisons being made and better identifies the ambitious immigrant-origin students and the less ambitious native students. This is potentially relevant from a policy perspective because it identifies which students could be targeted by interventions. On the one hand, disadvantaged immigrantorigin students should be given extra support to obtain the educational achievement in lower secondary education that can sustain their high aspirations. On the other hand, disadvantaged native students should be sustained academically but also incited to aim for more prestigious academic tracks. Results are also relevant from a methodological point of view, since results of my counterfactual analyses varied when triple interaction weights were used.

This paper also highlighted the importance of investigating immigrant-native inequalities beyond a single educational transition. Ethnic disadvantages after the transition to upper secondary education were substantively large, especially if we consider that the negative effects of dropout may be more consequential for immigrant-origin students. Dropout could be a critical negative shock in assimilation pathways, and could have especially strong spillover effects on other life course domains and behaviors. For high-aiming immigrant-origin students, failed aspirations are likely to create greater disappointment and disillusionment, with more severe psychological costs and consequences on their social outcomes, such as sense of belonging, attitudes towards the host country and voting behavior. Future research should adopt a life course perspective and investigate the consequences of positive ethnic choice effects on the subsequent educational, labor and social outcomes of immigrant-origin students.

In line with previous evidence (Birkelund, 2020; Dollmann and Weißmann, 2019), my results show that positive ethnic choice effects explain a significant portion of the disadvantage experienced by immigrant-origin students in upper secondary education. As predicted by the immigrant aspiration attainment paradox, many immigrant-origin students make ambitious enrolment decisions despite their low academic performance. Many of them are unable to compensate for the initial disadvantage and end up dropping out. My counterfactual analyses also show that immigrant-native gaps in academic achievement in lower secondary education are responsible for a large portion of immigrant-origin students' disadvantages after the transition. These findings indicate that ethnic educational inequalities should be addressed by closing early gaps in educational achievement before educational transitions, since their effects persist throughout educational trajec- 
tories.

This study, like others before it, focuses on the perspective of the children of immigrants and investigates their ambitious decisions. However, an equally valid and interesting perspective is the one of investigating the comparatively low aspirations of native students (Birkelund, 2020). My results show that low-performing and lower-class native students are the least likely to enrol in academic upper secondary education. Future work should investigate the disenfranchisement of these students and how they can benefit from positive encounters with high-aspiring immigrant-origin students.

This study has several limitations that could be addressed in future work. The small sample sizes provided limited power for many of the tests that were carried out in the analyses. For example, some of the three-way interactions between immigrant background, social class and prior academic achievement were not estimateable. The small sample sizes also implied a choice of rather broad classifications of parental occupational class and the use of quintiles in academic performance, rather than more fine-grained distinctions. Sample size issues also made the estimation of differences between different immigrant groups unfeasible. Moreover, the lack of data on the completion of upper secondary education for the 2007 cohort limited results on attainment to the 1995 cohort. Future research should overcome these limitations by replicating some of the analyses with new and better data, perhaps from surveys oversampling students with an immigrant background.

Despite the shortcomings, this paper has extended previous findings from different countries to the case of France. This represents an interesting contribution to the literature, because of the institutional differences between the French system and the ones of other countries where results were already available. Moreover, the results of my analyses were fairly stable across the two rounds of the survey used, despite the difference of twelve years between them and the differences in the background characteristics of immigrant-origin students. Future research could investigate ethnic differences in educational decisions across different educational contexts to capture the effect of institutional features such as rules governing educational transitions or the desirability of vocational options (Jackson et al., 2012; Tjaden and Hunkler, 2017). Moreover, researchers may also compare ethnic choice effects over time to investigate differences across more recent and older immigrant groups and the effects of assimilation over time.

\section{Notes}

\footnotetext{
${ }^{1}$ I use the term "immigrant-native gaps" to refer to the gaps between the children of immigrants and those of natives. I hope the reader will excuse the use of this misnomer to improve the readability of the text.

${ }^{2}$ In the round of 2007 , the country of origin variable is more detailed and identifies individuals from Sahelian Africa and the Guinean Gulf, other than the general category "Other African country". By contrast, the round of 1995 only includes the broad broad category. To make information comparable, I aggregated the other origin countries into "Other African Country". This comes with small risks of biases since the origin of migrants from Africa has changed marginally between the two rounds, the only
} 
difference is that the round of 2007 had a larger sample that allowed for the identification of more groups.

${ }^{3}$ In the round of 1995, information on grades was gathered through the questionnaire on the orientation procedure to enrol in upper secondary completed by school principals. The response rate was of $90 \%$ in the first year and $79 \%$ in the second.

${ }^{4}$ Students sampled in the survey all enter lower secondary education for the first time and at the same time, so their educational outcomes are measured simultaneously unless they repeat a grade in lower secondary education. For this reason I distinguish between those who do and do not, but I do not consider whether students repeated a grade in primary education.

${ }^{5}$ For students who arrive to the end of lower secondary education one year late and are also retained in last year of lower secondary education, the outcome for this variable is grade repetition.

${ }^{6}$ The data only allows me to identify whether students completed the general track by 2004, which is two years after the expected time based on entrance to lower secondary education in 1995. Students outside this range have ether dropped out or repeated a grade at least three times in lower or upper secondary education and I consider them as not having completed the track.

${ }^{7}$ Students who repeat the last year of lower secondary education have class grades measured in two occasions: at the end of year they end up repeating and at the end of the following one (which is when I measure the enrolment outcome variable). I assign these students their class grades from the following one.

${ }^{8} \mathrm{I}$ also assign a weight of 1 to all immigrant-origin students from the upper class in the 1995 cohort because of the very large uncertainty associated with their performance-specific probabilities of enrolment in the GT track (see Figure 3).

${ }^{9}$ The predicted probabilities presented in Figure 2 are reported in tabular form in Appendix C.

${ }^{10}$ The predicted probabilities presented in Figure 3 are reported in tabular form in Appendix C.

${ }^{11}$ I ran additional analyses for upper class students using a continuous measure of standardized prior academic achievement and calculated predicted enrolment probabilities at levels of achievement corresponding to the quintiles of the distribution. Results presented in Appendix C confirm that there were no significant differences in immigrant-native differences in enrolment choices among upper class students at each level of previous academic performance.

${ }^{12}$ Differences between coefficients were not statistically significant due to small sample sizes and low power of the tests. However, reductions in gaps between Models 1 and 2 are comparable in size to previous research (Birkelund, 2020), which suggests that results are accurate but not precisely esimated

\section{References}

Bernardi, F. (2014). Compensatory Advantage as a Mechanism of Educational Inequality: A Regression Discontinuity Based on Month of Birth. Sociology of Education, 87(2):7488 .

Bernardi, F. and Triventi, M. (2018). Compensatory advantage in educational transitions: Trivial or substantial? A simulated scenario analysis. Acta Sociologica, page 000169931878095.

Birkelund, J. F. (2020). Aiming High and Missing the Mark? Educational Choice, Dropout Risk, and Achievement in Upper Secondary Education among Children of Immigrants in Denmark. European Sociological Review, 36(3):18.

Boudon, R. (1974). Education, Opportunity, and Social Inequality: Changing Prospects in Western Society. 
Bradley, S. and Lenton, P. (2007). Dropping out of post-compulsory education in the UK: An analysis of determinants and outcomes. Journal of Population Economics, 20(2):299-328.

Breen, R. and Goldthorpe, J. H. (1997). Explaining educational differentials: Towards a formal rational action theory. Rationality and Society, 9(3):275-305.

Brinbaum, Y. (2019). Trajectoires scolaires des enfants d'immigrés jusqu'au baccalauréat : rôle de l'origine et du genre - Résultats récents. Education ES Formation, n 100:73104.

Brinbaum, Y. and Cebolla-Boado, H. (2007). The school careers of ethnic minority youth in France: Success or disillusion? Ethnicities, 7(3):445-474.

Buchmann, M. C. and Kriesi, I. (2011). Transition to Adulthood in Europe. Annual Review of Sociology, 37(1):481-503.

Cebolla-Boado, H., González Ferrer, A., and Nuhoḡlu Soysal, Y. (2021). It is all about "Hope": Evidence on the immigrant optimism paradox. Ethnic and Racial Studies, $44(2): 252-271$.

DEPP (2008). Suivi Des Élèves Du Panel 1995 Au Cours de Leurs Etudes Secondaires. Fichier Historique 1995-2006. INSEE (Institut nationale de la statistique et des études économiques)., Presentation du panel et documentation. Paris.

DEPP (2015). Panel d'élèves Du Second Degree Recrutement 200\%. Fichier d'étude. Presentation Du Panel et Documentation. INSEE (Institut nationale de la statistique et des études économiques)., Presentation du panel et documentation. Paris.

Dollmann, J. (2017). Positive choices for all? SES- and gender-specific premia of immigrants at educational transitions. Research in Social Stratification and Mobility, 49:20-31.

Dollmann, J. and Weißmann, M. (2019). The Story after Immigrants' Ambitious Educational Choices: Real Improvement or Back to Square One? European Sociological Review, page jcz042.

Erikson, R., Goldthorpe, J. H., Jackson, M., Yaish, M., and Cox, D. R. (2005). On class differentials in educational attainment. Proceedings of the National Academy of Sciences, 102(27):9730-9733.

Fernández-Reino, M. (2016). Immigrant optimism or anticipated discrimination? Explaining the first educational transition of ethnic minorities in England. Research in Social Stratification and Mobility, 46:141-156.

Fortin, N., Lemieux, T., and Firpo, S. (2011). Decomposition Methods in Economics. In Handbook of Labor Economics, volume 4, pages 1-102. Elsevier. 
Gil-Hernández, C. J. and Gracia, P. (2018). Adolescents' educational aspirations and ethnic background: The case of students of African and Latin American migrant origins in Spain. Demographic Research, 38:577-618.

Gupta, P. D. (1994). Standardization and decomposition of rates from cross-classified data. 50(3):171-196.

Heath, A. and Brinbaum, Y. (2007). Explaining ethnic inequalities in educational attainment. Ethnicities, 7(3):291-304.

Hernán, M. A. and Robins, J. M. (2020). Causal Inference: What If. Chapman \& Hall/CRC, Boca Ranton.

Holm, A., Hjorth-Trolle, A., and Jæger, M. M. (2019). Signals, Educational DecisionMaking, and Inequality. European Sociological Review, 35(4):447-460.

Ichou, M. (2014). Who They Were There: Immigrants' Educational Selectivity and Their Children's Educational Attainment. European Sociological Review, 30(6):750-765.

INSEE (2020). Recensement de La Population $201 \%$.

Jackson, M., Jonsson, J. O., and Rudolphi, F. (2012). Ethnic Inequality in Choice-driven Education Systems: A Longitudinal Study of Performance and Choice in England and Sweden. Sociology of Education, 85(2):158-178.

Jonsson, J. O., Kilpi-Jakonen, E., and Rudolphi, F. (2014). Ethnic Differences in Early School-Leaving: An International Comparison, pages 95-118. Oxford University Press, Oxford.

Jonsson, J. O. and Rudolphi, F. (2011). Weak Performance-Strong Determination: School Achievement and Educational Choice among Children of Immigrants in Sweden. European Sociological Review, 27(4):487-508.

Kalmijn, M. and Kraaykamp, G. (2003). Dropout and Downward Mobility in the Educational Career: An Event-History Anaylsis of Ethnic Schooling Differences in the Netherlands. Educational Research and Evaluation, 9(3):265-287.

Kao, G. and Tienda, M. (1995). Optimism and Achievement: The Educational Performance of Immigrant Youth. Social Science Quarterly, 76(1):1-19.

Kao, G. and Tienda, M. (1998). Educational Aspirations of Minority Youth. American Journal of Education, 106(3):349-384.

Kilpi-Jakonen, E. (2011). Continuation to upper secondary education in Finland: Children of immigrants and the majority compared. Acta Sociologica, 54(1):77-106.

Liem, J. H., Lustig, K., and Dillon, C. (2010). Depressive Symptoms and Life Satisfaction Among Emerging Adults: A Comparison of High School Dropouts and Graduates. Journal of Adult Development, 17(1):33-43. 
Pirus, C. (2013). Le déroulement de la procédure d'orientation en fin de troisième reste marqué par de fortes disparités scolaires et sociales. Note d'Information n. 13-24., DEPP (Direction de l'évaluation, de la prospective et de la performance).

Polavieja, J. G., Fernández-Reino, M., and Ramos, M. (2018). Are Migrants Selected on Motivational Orientations? Selectivity Patterns amongst International Migrants in Europe. European Sociological Review, 34(5):570-588.

Salikutluk, Z. (2016). Why Do Immigrant Students Aim High? Explaining the Aspiration-Achievement Paradox of Immigrants in Germany. European Sociological Review, 32(5):581-592.

Storen, L. A. and Helland, H. (2010). Ethnicity Differences in the Completion Rates of Upper Secondary Education: How Do the Effects of Gender and Social Background Variables Interplay? European Sociological Review, 26(5):585-601.

Tjaden, J. D. and Hunkler, C. (2017). The optimism trap: Migrants' educational choices in stratified education systems. Social Science Research, 67:213-228.

Tjaden, J. D. and Scharenberg, K. (2017). Ethnic choice effects at the transition into upper-secondary education in Switzerland. Acta Sociologica, 60(4):309-324.

van de Werfhorst, H. G. and Heath, A. (2019). Selectivity of Migration and the Educational Disadvantages of Second-Generation Immigrants in Ten Host Societies. European Journal of Population, 35(2):347-378.

Van De Werfhorst, H. G. and Van Tubergen, F. (2007). Ethnicity, schooling, and merit in the Netherlands. Ethnicities, 7(3):416-444. 


\section{Appendix A - Description of additional control varaibles and of repeaters and non-repeaters in the sample}

Table A1: Descriptive statistics for additional control variables

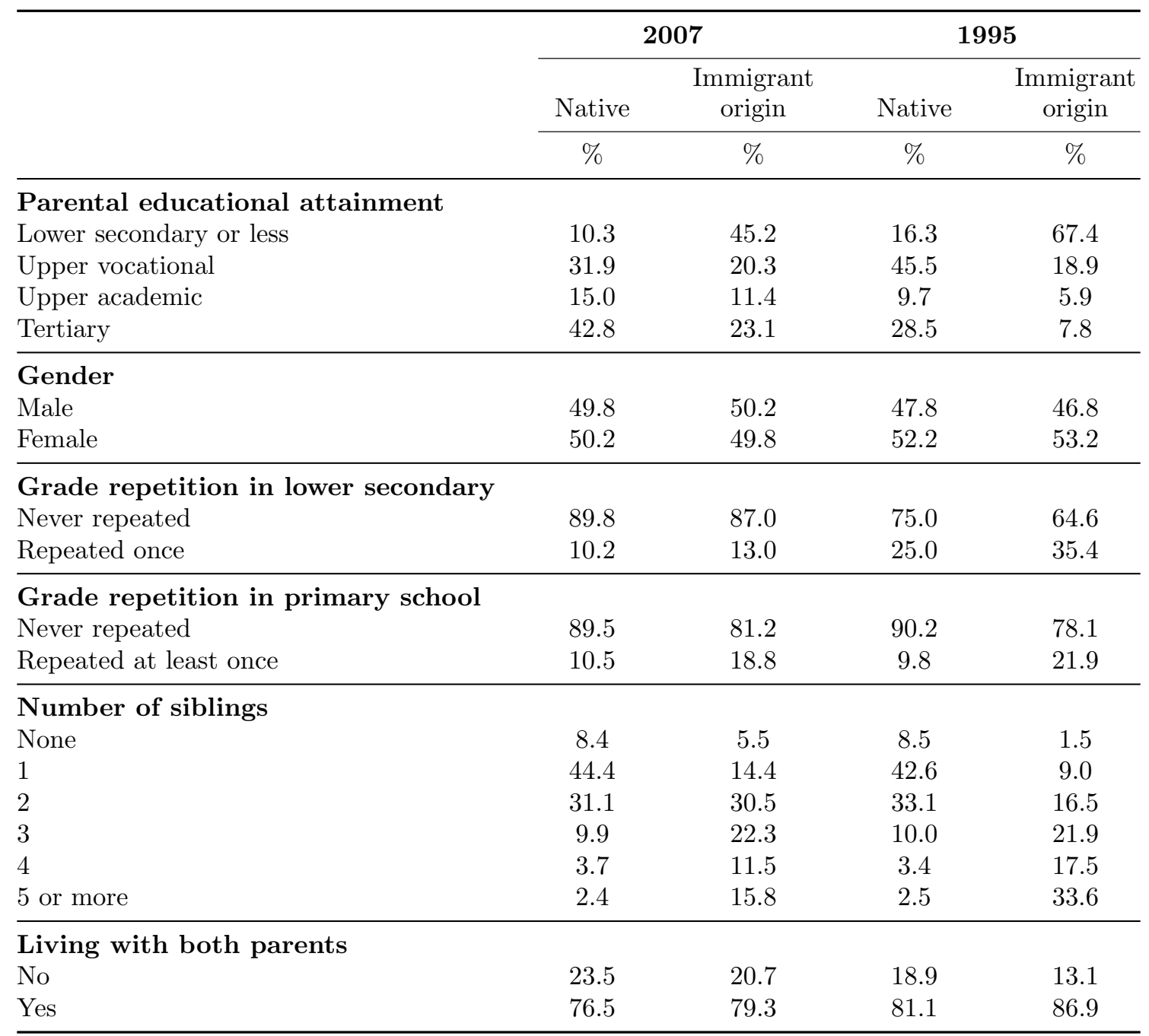

Source: Panel d'élèves du second degré 2007 and 1995 cohorts, own calculations. 
Table A2: Comparison of students in the sample who did and did not repeat a grade in lower secondary education, 2007 cohort

\begin{tabular}{lcccc}
\hline & \multicolumn{2}{c}{ Non-repeaters } & \multicolumn{2}{c}{ Repeaters } \\
\cline { 2 - 5 } & Native & $\begin{array}{c}\text { Immigrant } \\
\text { origin }\end{array}$ & Native & $\begin{array}{c}\text { Immigrant } \\
\text { origin }\end{array}$ \\
\cline { 2 - 5 } & $\%$ & $\%$ & $\%$ & $\%$ \\
\hline Parental occupational class & & & & \\
Upper & 27.0 & 14.3 & 12.8 & 5.2 \\
Intermediate & 64.4 & 56.9 & 73.2 & 66.9 \\
Working & 8.6 & 28.8 & 13.9 & 27.9 \\
\hline Parental educational attainment & & & & \\
Lower secondary or less & 9.5 & 43.5 & 16.9 & 56.6 \\
Upper vocational & 30.4 & 20.3 & 45.5 & 20.2 \\
Upper academic & 15.0 & 11.5 & 15.6 & 10.4 \\
Tertiary & 45.1 & 24.6 & 22.0 & 12.8 \\
\hline Quintiles of grades in lower secondary & & & & \\
Bottom & 15.2 & 30.5 & 38.9 & 56.0 \\
2nd & 18.6 & 20.3 & 31.3 & 26.2 \\
3rd & 21.5 & 19.3 & 17.7 & 12.7 \\
4th & 22.4 & 15.3 & 9.5 & 3.5 \\
Top & 22.3 & 14.6 & 2.6 & 1.6 \\
\hline Enrollment after compulsory education & & & & \\
Vocational track or grade repetition & 27.4 & 34.1 & 73.8 & 63.1 \\
General and technological (GT) track & 72.6 & 65.9 & 26.2 & 36.9 \\
\hline
\end{tabular}

Source: Panel d'élèves du second degré 2007 cohort, own calculations. 
Table A3: Comparison of students in the sample who did and did not repeat a grade in lower secondary education, 1995 cohort

\begin{tabular}{lcccc}
\hline & \multicolumn{2}{c}{ Non-repeaters } & \multicolumn{2}{c}{ Repeaters } \\
\cline { 2 - 5 } & Native & $\begin{array}{c}\text { Immigrant } \\
\text { origin }\end{array}$ & Native & $\begin{array}{c}\text { Immigrant } \\
\text { origin }\end{array}$ \\
\cline { 2 - 5 } & $\%$ & $\%$ & $\%$ & $\%$ \\
\hline Parental occupational class & & & & \\
Upper & 24.7 & 7.2 & 10.9 & 1.9 \\
Intermediate & 62.4 & 35.4 & 69.2 & 42.7 \\
Working & 12.8 & 57.4 & 19.9 & 55.4 \\
\hline Parental educational attainment & & & & \\
Lower secondary or less & 13.7 & 65.2 & 23.9 & 71.2 \\
Upper vocational & 42.7 & 18.2 & 54.1 & 20.2 \\
Upper academic & 10.2 & 6.3 & 8.2 & 5.2 \\
Tertiary & 33.4 & 10.3 & 13.8 & 3.4 \\
\hline Quintiles of grades in lower secondary & & & & \\
Bottom & 12.2 & 30.7 & 42.3 & 64.7 \\
2nd & 16.5 & 19.0 & 30.6 & 21.5 \\
3rd & 23.7 & 19.3 & 19.0 & 10.0 \\
4th & 21.5 & 16.4 & 6.3 & 3.3 \\
Top & 26.1 & 14.6 & 1.8 & 0.4 \\
\hline Enrollment after compulsory education & & & & \\
Vocational track or grade repetition & 18.1 & 28.3 & 72.0 & 69.1 \\
General and technological (GT) track & 81.9 & 71.7 & 28.0 & 30.9 \\
\hline
\end{tabular}

Source: Panel d'élèves du second degré 1995 cohort, own calculations. 


\section{Appendix B - Simple ethnic choice effects: robustness and additional analyses}

Table B1: Average marginal effects from logistic models predicting enrollment in the general and technological track after compulsory education controlling for grade repetition in lower secondary education, 2007 cohort

\begin{tabular}{|c|c|c|c|c|c|c|}
\hline \multirow[b]{2}{*}{ Origin (reference: Native students } & \multicolumn{2}{|c|}{$\begin{array}{c}\text { Model } 1 \\
\text { (no controls) }\end{array}$} & \multicolumn{2}{|c|}{$\begin{array}{c}\text { Model } 2 \\
(+ \text { class Controls })\end{array}$} & \multicolumn{2}{|c|}{$\begin{array}{c}\text { Model } 3 \\
(+ \text { grades controls })\end{array}$} \\
\hline & & & & & & \\
\hline Immigrant-origin students & $\begin{array}{c}-0.057^{* * *} \\
(0.012)\end{array}$ & & $\begin{array}{c}0.018 \\
(0.011)\end{array}$ & & $\begin{array}{l}0.094^{* * *} \\
(0.0072)\end{array}$ & \\
\hline \multicolumn{7}{|c|}{ Origin (reference: Native students) } \\
\hline North Africa & & $\begin{array}{l}-0.030^{*} \\
(0.014)\end{array}$ & & $\begin{array}{l}0.037^{* *} \\
(0.013)\end{array}$ & & $\begin{array}{l}0.10^{* * *} \\
(0.0086)\end{array}$ \\
\hline Turkey & & $\begin{array}{l}-0.12^{* *} \\
(0.036)\end{array}$ & & $\begin{array}{c}0.043 \\
(0.029)\end{array}$ & & $\begin{array}{c}0.087^{* * *} \\
(0.019)\end{array}$ \\
\hline Other African country & & $\begin{array}{c}-0.11^{* * *} \\
(0.026)\end{array}$ & & $\begin{array}{l}-0.054^{*} \\
(0.023)\end{array}$ & & $\begin{array}{c}0.067^{* * *} \\
(0.015)\end{array}$ \\
\hline Observations & 20966 & 20966 & 20966 & 20966 & 20966 & 20966 \\
\hline Pseudo $\mathrm{R}^{2}$ & 0.00088 & 0.0013 & 0.085 & 0.085 & 0.39 & 0.39 \\
\hline
\end{tabular}

Notes: The table reports average marginal effects from logistic regressions with standard errors in parentheses. Model 1 presents gross gaps, Model 2 controls for parental occupational class, and Model 3 controls for students' quintile of compulsory school grades before making the transition as well as an indicator of whether they repeated a grade in lower secondary education. $* p<0.05, * * p<0.01, * * * p<0.001$.

Source: Panel d'élèves du second degré 2007 cohort, own calculations.

Table B2: Average marginal effects from logistic models predicting enrollment in the general and technological track after compulsory education controlling for grade repetition in lower secondary education, 1995 cohort

\begin{tabular}{|c|c|c|c|c|c|c|}
\hline \multirow{2}{*}{ Origin (reference: Native students } & \multicolumn{2}{|c|}{$\begin{array}{c}\text { Model 1 } \\
\text { (no controls) }\end{array}$} & \multicolumn{2}{|c|}{$\begin{array}{c}\text { Model } 2 \\
(+ \text { class Controls }) \\
\end{array}$} & \multicolumn{2}{|c|}{$\begin{array}{c}\text { Model } 3 \\
(+ \text { grades controls } \\
\end{array}$} \\
\hline & & & & & & \\
\hline Immigrant-origin students & $\begin{array}{r}-0.11^{* * *} \\
(0.021)\end{array}$ & & $\begin{array}{l}0.0096 \\
(0.019)\end{array}$ & & $\begin{array}{l}0.10^{* * *} \\
(0.012)\end{array}$ & \\
\hline \multicolumn{7}{|c|}{ Origin (reference: Native students) } \\
\hline North Africa & & $\begin{array}{r}-0.10^{* * *} \\
(0.023)\end{array}$ & & $\begin{array}{c}0.025 \\
(0.020)\end{array}$ & & $\begin{array}{l}0.11^{* * *} \\
(0.013)\end{array}$ \\
\hline Turkey & & $\begin{array}{r}-0.27^{* * *} \\
(0.074)\end{array}$ & & $\begin{array}{l}-0.088 \\
(0.071)\end{array}$ & & $\begin{array}{c}0.017 \\
(0.040)\end{array}$ \\
\hline Other African country & & $\begin{array}{l}-0.089 \\
(0.056)\end{array}$ & & $\begin{array}{l}-0.036 \\
(0.052)\end{array}$ & & $\begin{array}{l}0.085^{* *} \\
(0.032)\end{array}$ \\
\hline Observations & 8476 & 8476 & 8476 & 8476 & 8476 & 8476 \\
\hline Pseudo $\mathrm{R}^{2}$ & 0.0031 & 0.0036 & 0.074 & 0.075 & 0.45 & 0.45 \\
\hline
\end{tabular}

Notes: The table reports average marginal effects from logistic regressions with standard errors in parentheses. Model 1 presents gross gaps, Model 2 controls for parental occupational class, and Model 3 controls for students' quintile of compulsory school grades before making the transition as well as an indicator of whether they repeated a grade in lower secondary education.

* $p<0.05$, ** $p<0.01$, *** $p<0.001$.

Source: Panel d'élèves du second degré 1995 cohort, own calculations. 
Table B3: Average marginal effects from logistic models predicting enrollment in the general and technological track after compulsory education among students who did and did not repeat a grade in lower secondary education

\begin{tabular}{|c|c|c|c|c|c|c|}
\hline & \multicolumn{3}{|c|}{2007} & \multicolumn{3}{|c|}{1995} \\
\hline & $\begin{array}{c}\text { Model } 1 \\
\text { (No cont.) }\end{array}$ & $\begin{array}{l}\text { Model } 2 \\
(+ \text { class })\end{array}$ & $\begin{array}{c}\text { Model } 3 \\
\text { (+grades) }\end{array}$ & $\begin{array}{c}\text { Model } 1 \\
\text { (No cont.) }\end{array}$ & $\begin{array}{l}\text { Model } 2 \\
(+ \text { class })\end{array}$ & $\begin{array}{c}\text { Model 3 } \\
\text { (+grades) }\end{array}$ \\
\hline \multicolumn{7}{|c|}{ Panel A: Non-repeaters } \\
\hline Immigrant-native gap & $\begin{array}{c}-0.066^{* * *} \\
(0.013)\end{array}$ & $\begin{array}{l}0.0086 \\
(0.011)\end{array}$ & $\begin{array}{l}0.080^{* * *} \\
(0.0071)\end{array}$ & $\begin{array}{c}-0.10^{* * *} \\
(0.023)\end{array}$ & $\begin{array}{c}0.011 \\
(0.018)\end{array}$ & $\begin{array}{c}0.068^{* * *} \\
(0.012)\end{array}$ \\
\hline Observations & 18791 & 18791 & 18791 & 6374 & 6374 & 6374 \\
\hline Pseudo $\mathrm{R}^{2}$ & 0.0014 & 0.087 & 0.38 & 0.0041 & 0.084 & 0.40 \\
\hline Panel B: Repeaters & & & & & & \\
\hline Immigrant-native gap & $\begin{array}{c}0.11^{* *} \\
(0.033) \\
\end{array}$ & $\begin{array}{l}0.15^{* * *} \\
(0.034)\end{array}$ & $\begin{array}{l}0.21^{* * *} \\
(0.032)\end{array}$ & $\begin{array}{c}0.029 \\
(0.033)\end{array}$ & $\begin{array}{l}0.098^{* *} \\
(0.036)\end{array}$ & $\begin{array}{l}0.19^{* * *} \\
(0.032)\end{array}$ \\
\hline Observations & 2175 & 2175 & 2175 & 2102 & 2102 & 2102 \\
\hline Pseudo $\mathrm{R}^{2}$ & 0.0045 & 0.042 & 0.17 & 0.00031 & 0.037 & 0.19 \\
\hline
\end{tabular}

Notes: The table reports average marginal effects from logistic regressions with standard errors in parentheses. Model 1 presents gross gaps, Model 2 controls for parental occupational class, and Model 3 controls for students' quintile of compulsory school grades before making the transition.

* $p<0.05$, ** $p<0.01$, *** $p<0.001$.

Source: Panel d'élèves du second degré 2007 and 1995 cohorts, own calculations.

Table B4: Average marginal effects from logistic models predicting enrollment in the general and technological track after compulsory education, adding full set of control variables

\begin{tabular}{|c|c|c|c|c|}
\hline & $\begin{array}{c}(1) \\
\text { Model } 1 \\
\text { (no controls) }\end{array}$ & $\begin{array}{c}(2) \\
\text { Model } 2 \\
(+ \text { class Controls })\end{array}$ & $\begin{array}{c}(3) \\
\text { Model } 3 \\
(+ \text { grades controls })\end{array}$ & $\begin{array}{c}(4) \\
\text { Model } 4 \\
(+ \text { additional controls })\end{array}$ \\
\hline \multicolumn{5}{|c|}{ Panel A: Panel of 2007} \\
\hline Immigrant-native gap & $\begin{array}{c}-0.057^{* * *} \\
(0.012)\end{array}$ & $\begin{array}{c}0.018 \\
(0.011)\end{array}$ & $\begin{array}{l}0.094^{* * *} \\
(0.0072)\end{array}$ & $\begin{array}{l}0.11^{* * *} \\
(0.0073)\end{array}$ \\
\hline Observations & 20966 & 20966 & 20966 & 20196 \\
\hline Pseudo $\mathrm{R}^{2}$ & 0.00088 & 0.085 & 0.39 & 0.44 \\
\hline \multicolumn{5}{|c|}{ Panel B: Panel of 1995} \\
\hline Immigrant-native gap & $\begin{array}{c}-0.11^{* * *} \\
(0.021)\end{array}$ & $\begin{array}{l}0.0096 \\
(0.019)\end{array}$ & $\begin{array}{l}0.10^{* * *} \\
(0.012)\end{array}$ & $\begin{array}{l}0.13^{* * *} \\
(0.014)\end{array}$ \\
\hline Observations & 8476 & 8476 & 8476 & 7032 \\
\hline Pseudo $\mathrm{R}^{2}$ & 0.0031 & 0.074 & 0.45 & 0.48 \\
\hline \multicolumn{5}{|c|}{$\begin{array}{l}\text { Notes: The table reports average marginal effects from logistic regressions with standard errors in parentheses. Model } 1 \\
\text { presents gross gaps, Model } 2 \text { controls for parental occupational class and Model } 3 \text { additionally controls for students' quintile of } \\
\text { compulsory school grades before making the transition. Model } 4 \text { additionally controls for: students' gender, number of siblings, } \\
\text { whether they lived with both of their parents, a measure of parental education and indicators for whether students repeated a } \\
\text { grade in lower secondary or primary education. } \\
*^{*} p<0.05, * * p<0.01, * * * p<0.001 \text {. } \\
\text { Source: Panel d'élèves du second degré } 2007 \text { cohort, own calculations. }\end{array}$} \\
\hline
\end{tabular}




\section{Appendix C - Heterogeneous ethnic choice effects: ro- bustness and additional analyses}

Table C1: Predicted probabilities and 95\% confidence intervals for the top panel of Figure 2

\begin{tabular}{lllll}
\hline \hline & \multicolumn{2}{l}{$\mathbf{2 0 0 7}$} & $\mathbf{1 9 9 5}$ \\
\hline Native $\times$ Bottom & 0.174 & {$[0.159,0.188]$} & 0.193 & {$[0.172,0.214]$} \\
Native $\times$ 2nd & 0.556 & {$[0.540,0.571]$} & 0.570 & {$[0.547,0.594]$} \\
Native $\times$ 3rd & 0.770 & {$[0.757,0.783]$} & 0.790 & {$[0.771,0.809]$} \\
Native $\times$ 4th & 0.882 & {$[0.871,0.892]$} & 0.915 & {$[0.900,0.931]$} \\
Native $\times$ Top & 0.956 & {$[0.949,0.963]$} & 0.973 & {$[0.963,0.982]$} \\
Immigrant-origin $\times$ Bottom & 0.229 & {$[0.192,0.267]$} & 0.316 & {$[0.253,0.379]$} \\
Immigrant-origin $\times$ 2nd & 0.786 & {$[0.747,0.826]$} & 0.812 & {$[0.752,0.873]$} \\
Immigrant-origin $\times$ 3rd & 0.903 & {$[0.875,0.932]$} & 0.913 & {$[0.865,0.960]$} \\
Immigrant-origin $\times 4$ th & 0.948 & {$[0.923,0.973]$} & 0.950 & {$[0.906,0.993]$} \\
Immigrant-origin $\times$ Top & 0.974 & {$[0.953,0.994]$} & 0.972 & {$[0.932,1.011]$} \\
\hline Observations & 20966 & & 8476 & \\
\hline \hline
\end{tabular}

Source: Panel d'élèves du second degré 2007 and 1995 cohorts, own calculations.

Table C2: Predicted probabilities and 95\% confidence intervals for the bottom panel of Figure 2

\begin{tabular}{|c|c|c|c|c|}
\hline & \multicolumn{2}{|r|}{2007} & \multicolumn{2}{|r|}{1995} \\
\hline Native $\times$ Upper & 0.806 & {$[0.795,0.818]$} & 0.814 & {$[0.794,0.834]$} \\
\hline Native $\times$ Intermediate & 0.649 & {$[0.643,0.656]$} & 0.668 & {$[0.658,0.678]$} \\
\hline Native $\times$ Lower & 0.508 & {$[0.488,0.528]$} & 0.538 & {$[0.515,0.560]$} \\
\hline Immigrant-origin $\times$ Upper & 0.856 & {$[0.809,0.904]$} & 0.857 & {$[0.735,0.980]$} \\
\hline Immigrant-origin $\times$ Intermediate & 0.741 & {$[0.723,0.759]$} & 0.733 & {$[0.692,0.774]$} \\
\hline Immigrant-origin $\times$ Lower & 0.676 & {$[0.646,0.706]$} & 0.708 & {$[0.676,0.740]$} \\
\hline Observations & 20966 & & 8476 & \\
\hline
\end{tabular}

Source: Panel d'élèves du second degré 2007 and 1995 cohorts, own calculations. 
Table C3: Predicted probabilities and 95\% confidence intervals for Figure 3

\begin{tabular}{|c|c|c|c|c|}
\hline & \multicolumn{2}{|r|}{2007} & \multicolumn{2}{|r|}{1995} \\
\hline French upper-class $\times$ Bottom & 0.324 & {$[0.268,0.380]$} & 0.398 & {$[0.310,0.486]$} \\
\hline French upper-class $\times 2$ nd & 0.760 & {$[0.728,0.793]$} & 0.795 & {$[0.743,0.846]$} \\
\hline French upper-class $\times 3$ rd & 0.921 & {$[0.903,0.938]$} & 0.940 & {$[0.916,0.964]$} \\
\hline French upper-class $\times 4$ th & 0.972 & {$[0.962,0.981]$} & 0.980 & {$[0.965,0.994]$} \\
\hline French upper-class $\times$ Top & 0.994 & {$[0.990,0.998]$} & 0.990 & {$[0.982,0.999]$} \\
\hline French intermediate class $\times$ Bottom & 0.130 & {$[0.116,0.143]$} & 0.162 & {$[0.140,0.185]$} \\
\hline French intermediate class $\times 2$ nd & 0.512 & {$[0.493,0.531]$} & 0.561 & {$[0.531,0.591]$} \\
\hline French intermediate class $\times$ 3rd & 0.757 & {$[0.741,0.774]$} & 0.793 & {$[0.769,0.816]$} \\
\hline French intermediate class $\times 4$ th & 0.870 & {$[0.856,0.883]$} & 0.926 & {$[0.909,0.944]$} \\
\hline French intermediate class $\times$ Top & 0.948 & {$[0.938,0.958]$} & 0.971 & {$[0.960,0.982]$} \\
\hline French lower-class $\times$ Bottom & 0.0593 & {$[0.0397,0.0788]$} & 0.0694 & {$[0.0430,0.0958]$} \\
\hline French lower-class $\times 2$ nd & 0.336 & {$[0.289,0.382]$} & 0.342 & {$[0.282,0.401]$} \\
\hline French lower-class $\times 3$ rd & 0.486 & {$[0.432,0.540]$} & 0.609 & {$[0.546,0.672]$} \\
\hline French lower-class $\times 4$ th & 0.735 & {$[0.680,0.789]$} & 0.790 & {$[0.728,0.853]$} \\
\hline French lower-class $\times$ Top & 0.905 & {$[0.862,0.948]$} & 0.975 & {$[0.947,1.003]$} \\
\hline Migrant upper-class $\times$ Bottom & 0.421 & {$[0.198,0.643]$} & 0.511 & {$[0.0165,1.006]$} \\
\hline Migrant upper-class $\times 2$ nd & 0.812 & {$[0.661,0.963]$} & 0.752 & {$[0.330,1.174]$} \\
\hline Migrant upper-class $\times$ 3rd & 0.981 & {$[0.945,1.018]$} & . & . \\
\hline Migrant upper-class $\times 4$ th & 0.981 & {$[0.944,1.018]$} & . & . \\
\hline Migrant upper-class $\times$ Top & & & & \\
\hline Migrant intermediate class $\times$ Bottom & 0.163 & {$[0.125,0.201]$} & 0.229 & {$[0.144,0.314]$} \\
\hline Migrant intermediate class $\times 2$ nd & 0.736 & {$[0.679,0.792]$} & 0.795 & {$[0.677,0.914]$} \\
\hline Migrant intermediate class $\times 3 \mathrm{rd}$ & 0.900 & {$[0.858,0.942]$} & 0.834 & {$[0.721,0.947]$} \\
\hline Migrant intermediate class $\times 4$ th & 0.964 & {$[0.933,0.995]$} & 0.924 & {$[0.823,1.025]$} \\
\hline Migrant intermediate class $\times$ Top & 0.963 & {$[0.928,0.999]$} & 0.926 & {$[0.827,1.025]$} \\
\hline Migrant lower-class $\times$ Bottom & 0.105 & {$[0.0644,0.146]$} & 0.178 & {$[0.119,0.236]$} \\
\hline Migrant lower-class $\times 2$ nd & 0.691 & {$[0.605,0.777]$} & 0.681 & {$[0.574,0.788]$} \\
\hline Migrant lower-class $\times$ 3rd & 0.775 & {$[0.686,0.864]$} & 0.886 & {$[0.800,0.972]$} \\
\hline Migrant lower-class $\times 4$ th & 0.845 & {$[0.755,0.935]$} & 0.918 & {$[0.828,1.007]$} \\
\hline Migrant lower-class $\times$ Top & 0.954 & {$[0.895,1.013]$} & . & . \\
\hline Observations & 20897 & & 8428 & \\
\hline
\end{tabular}

Source: Panel d'élèves du second degré 2007 and 1995 cohorts, own calculations. 
Figure C1: Predicted probabilities of enrollment in the general and technological track after compulsory education among upper class students obtained from logistic regressions with 2-way interactions between immigrant background and a continuous measure of standardized lower secondary grades and computed at quintiles of the distribution of lower secondary grades

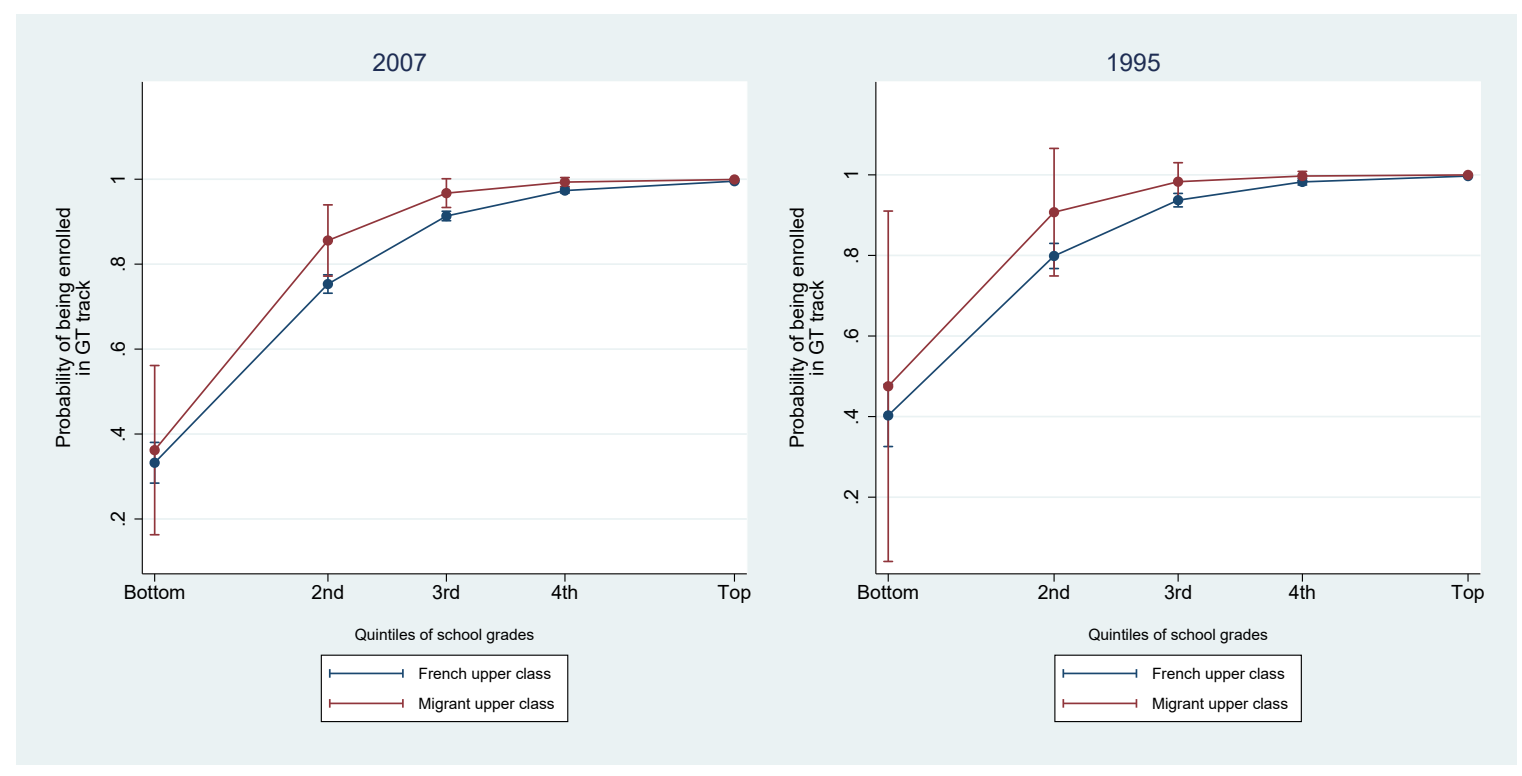

Notes: The figure shows predicted probabilities of enrollment in the general and technological track after compulsory education from logistic models including 2-way interactions of students' immigrant background and a continuous measure of standardized school grades in the last year of lower secondary education. Predicted probabilities were computed at the midpoints of the quintiles of school grades distribution in each cohort. Estimates are presented with 95 percent confidence intervals.

Source: Panel d'élèves du second degré 2007 and 1995 cohorts, own calculations. 
Figure C2: Predicted probabilities of enrollment in the general and technological track after compulsory education from logistic regressions with 3-way interactions between immigrant background, parental class and and quintiles of lower secondary grades, controlling for grade repetition in lower secondary education

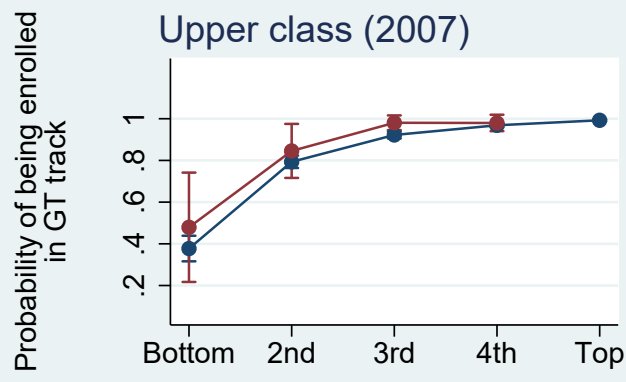

Quintiles of lower secondary grades
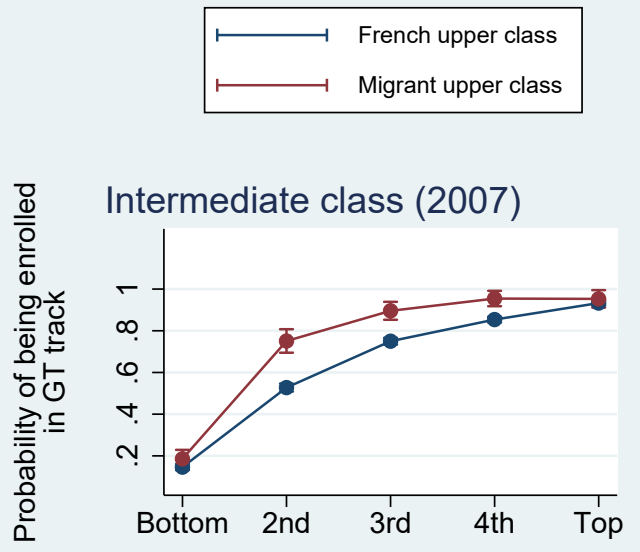

Quintiles of lower secondary grades
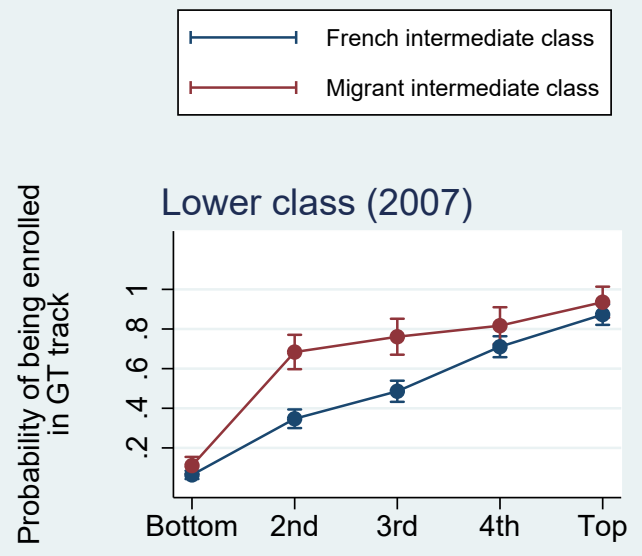

Quintiles of lower secondary grades

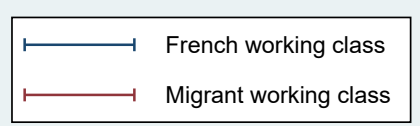

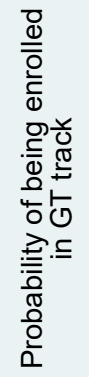

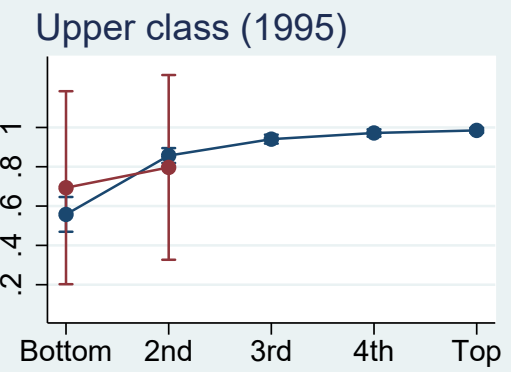

Quintiles of lower secondary grades
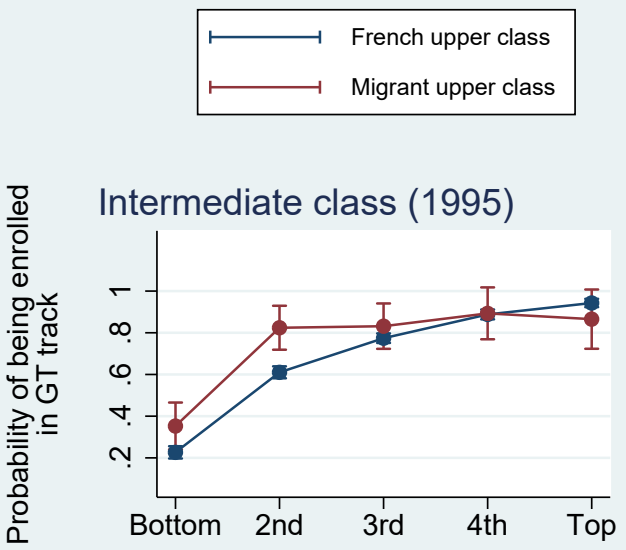

Quintiles of lower secondary grades

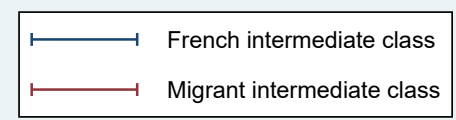

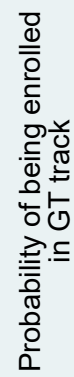

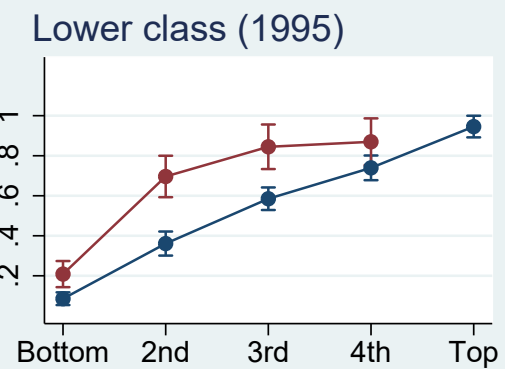

Quintiles of lower secondary grades

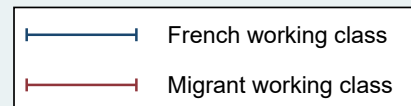

Notes: The figure shows predicted probabilities of enrollment in the general and technological track after compulsory education from logistic models including 3-way interactions of students' immigrant background, parental occupational class and quintiles of school grades in the last year of lower secondary education. Results are presented by comparing immigrant and native students in each social class and by quintiles of lower secondary grades. Estimates are presented with 95 percent confidence intervals.

Source: Panel d'élèves du second degré 2007 and 1995 cohorts, own calculations. 
Figure C3: Predicted probabilities of enrollment in the general and technological track after compulsory education from logistic regressions with 3-way interactions between immigrant background, parental class and and quintiles of lower secondary grades among non-repeaters
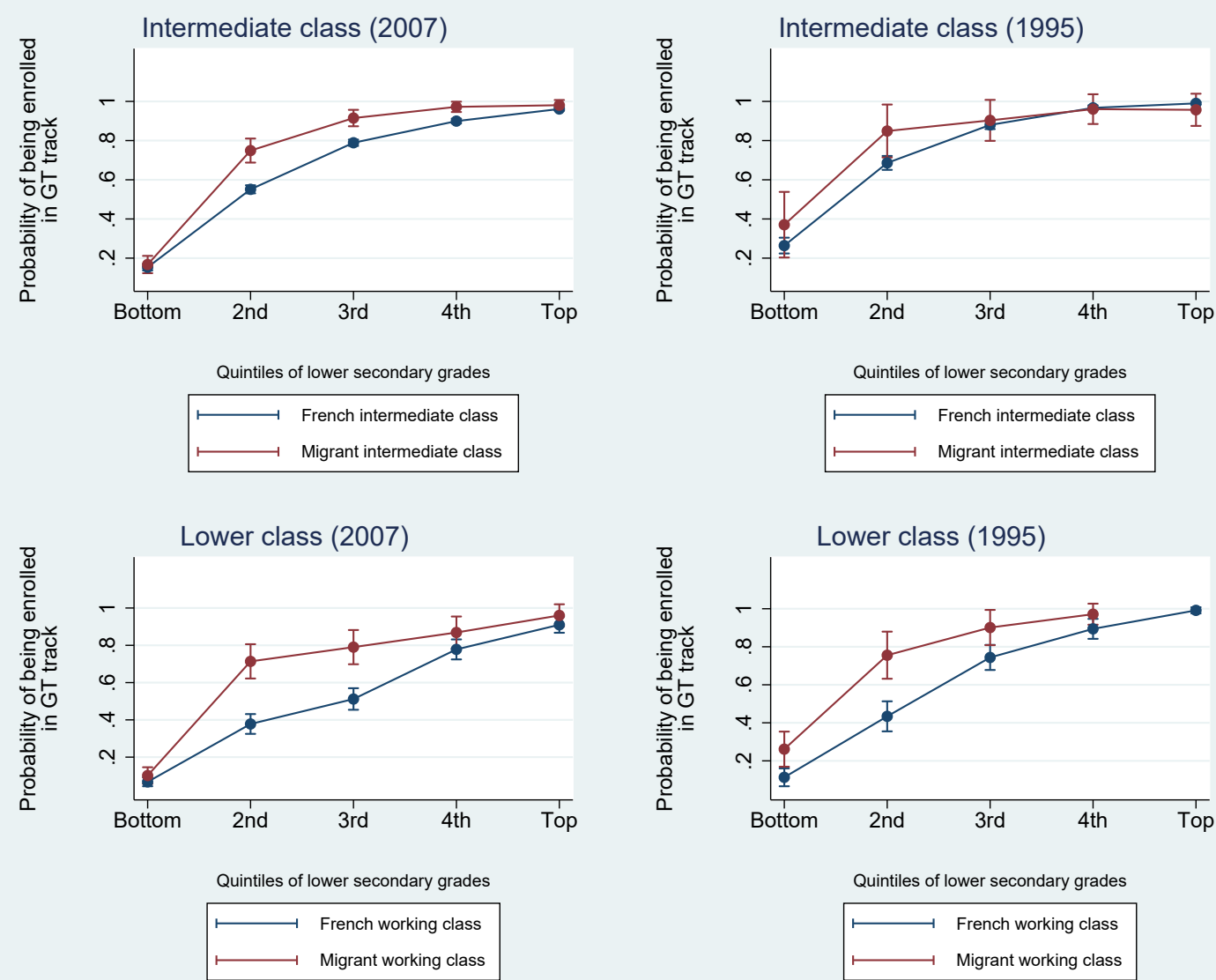

Notes: The figure shows predicted probabilities of enrollment in the general and technological track after compulsory education from logistic models including 3-way interactions of students' immigrant background, parental occupational class and quintiles of school grades in the last year of lower secondary education. Results are presented by comparing immigrant and native students in each social class and by quintiles of lower secondary grades. Estimates are presented with 95 percent confidence intervals.

Source: Panel d'élèves du second degré 2007 and 1995 cohorts, own calculations. 
Figure C4: Predicted probabilities of enrollment in the general and technological track after compulsory education from logistic regressions with 3-way interactions between immigrant background, parental class and and quintiles of lower secondary grades among repeaters
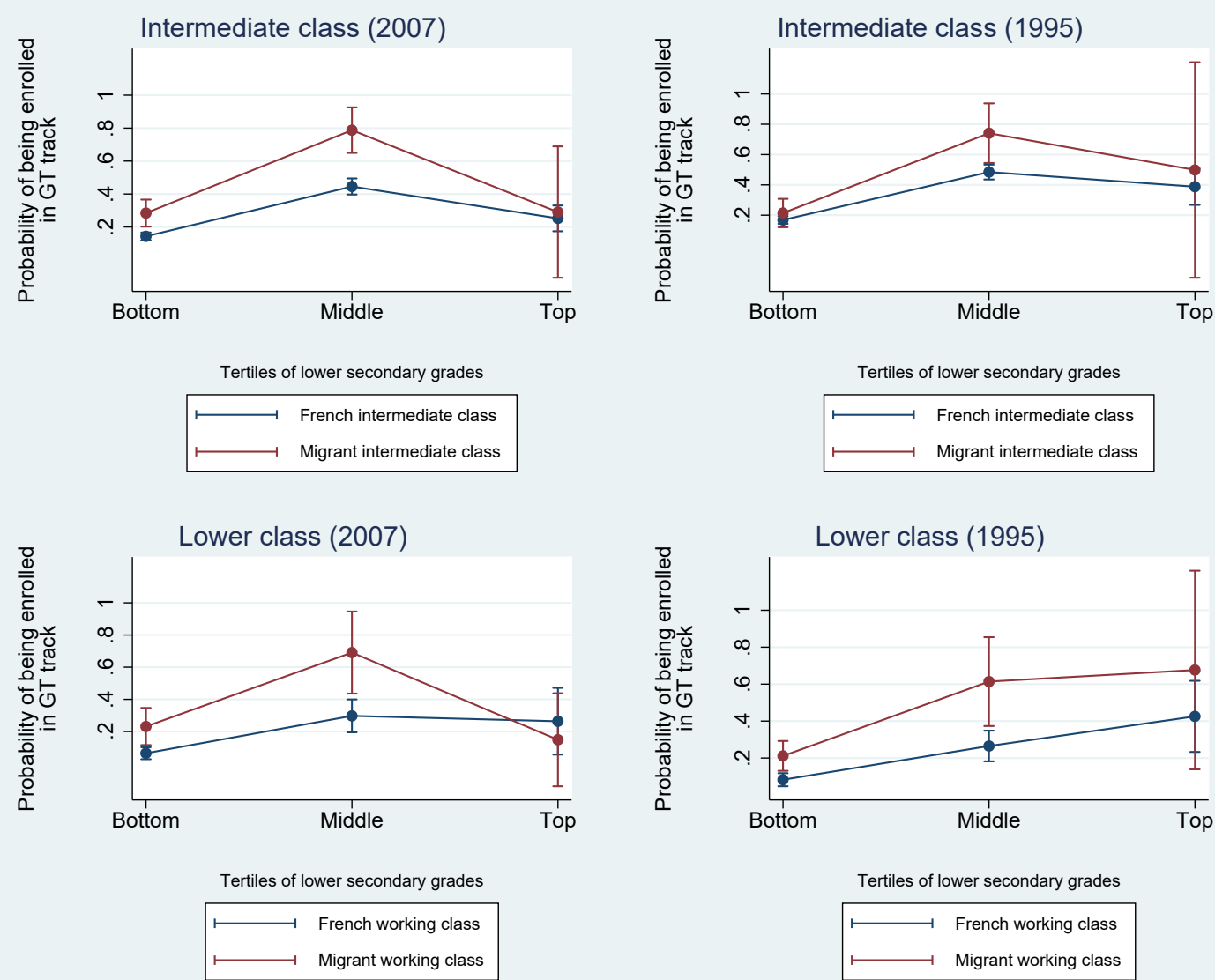

Notes: The figure shows predicted probabilities of enrollment in the general and technological track after compulsory education from logistic models including 3-way interactions of students' immigrant background, parental occupational class and tertiles of school grades in the last year of lower secondary education. Results are presented by comparing immigrant and native students in each social class and by quintiles of lower secondary grades. Estimates are presented with 95 percent confidence intervals.

Source: Panel d'élèves du second degré 2007 and 1995 cohorts, own calculations. 
Figure C5: Predicted probabilities of enrollment in the general and technological track after compulsory education from logistic regressions with 3-way interactions between immigrant background, parental class and and quintiles of lower secondary grades, accounting for full set of control variables
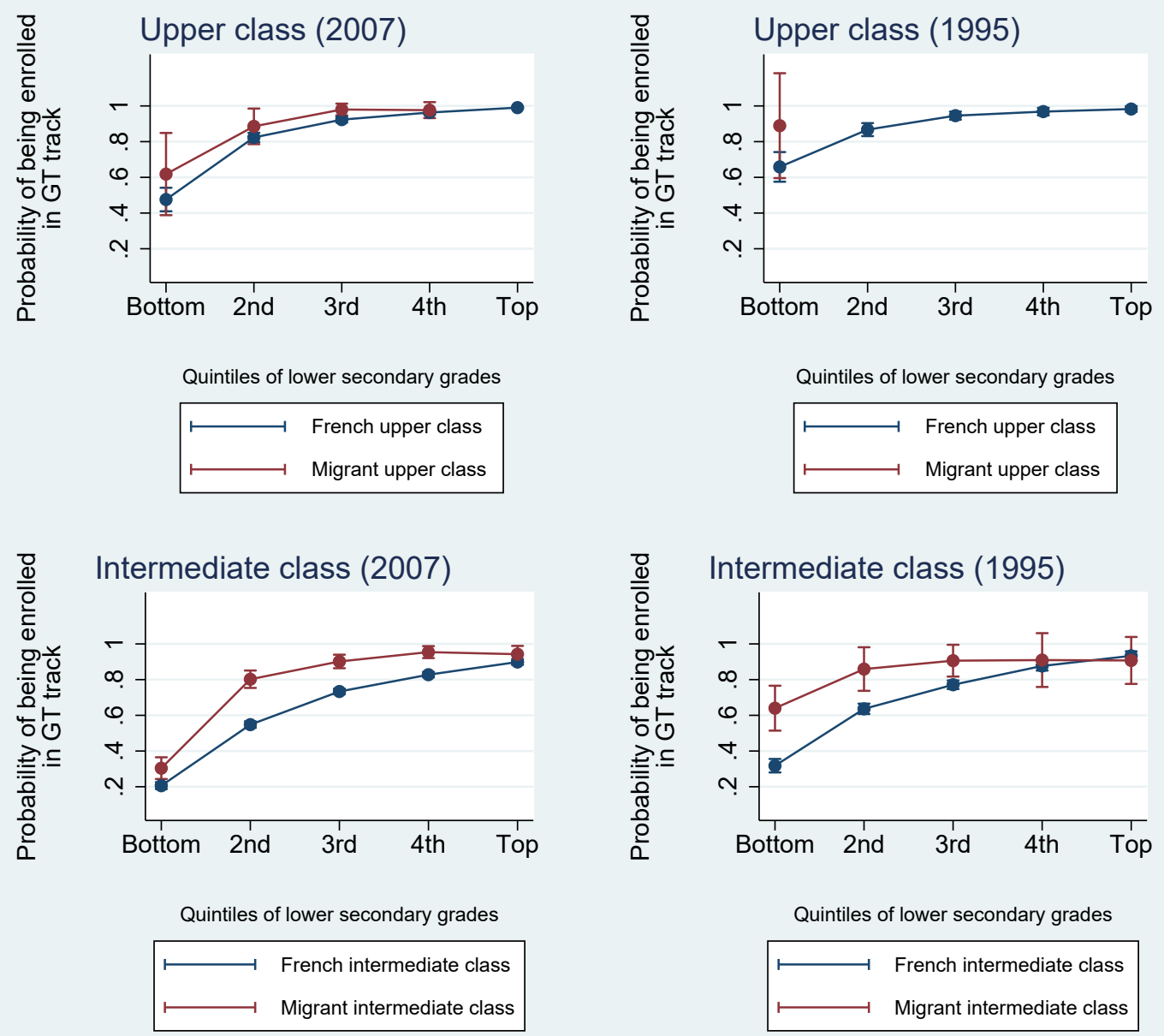

Quintiles of lower secondary grades

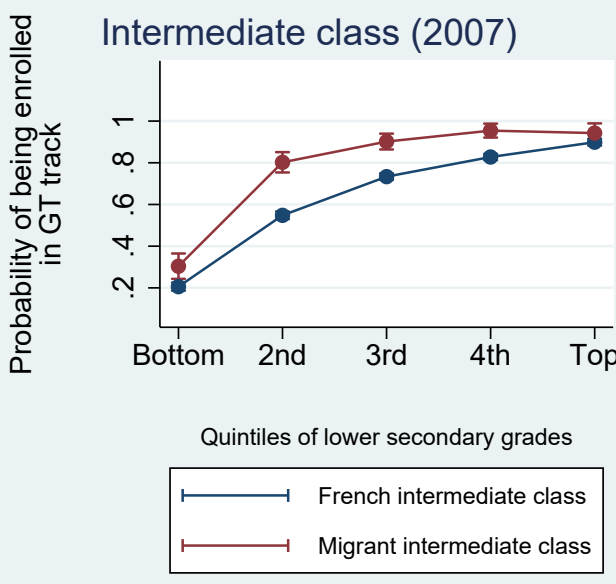

Quintiles of lower secondary grades

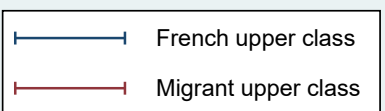

Quintiles of lower secondary grades
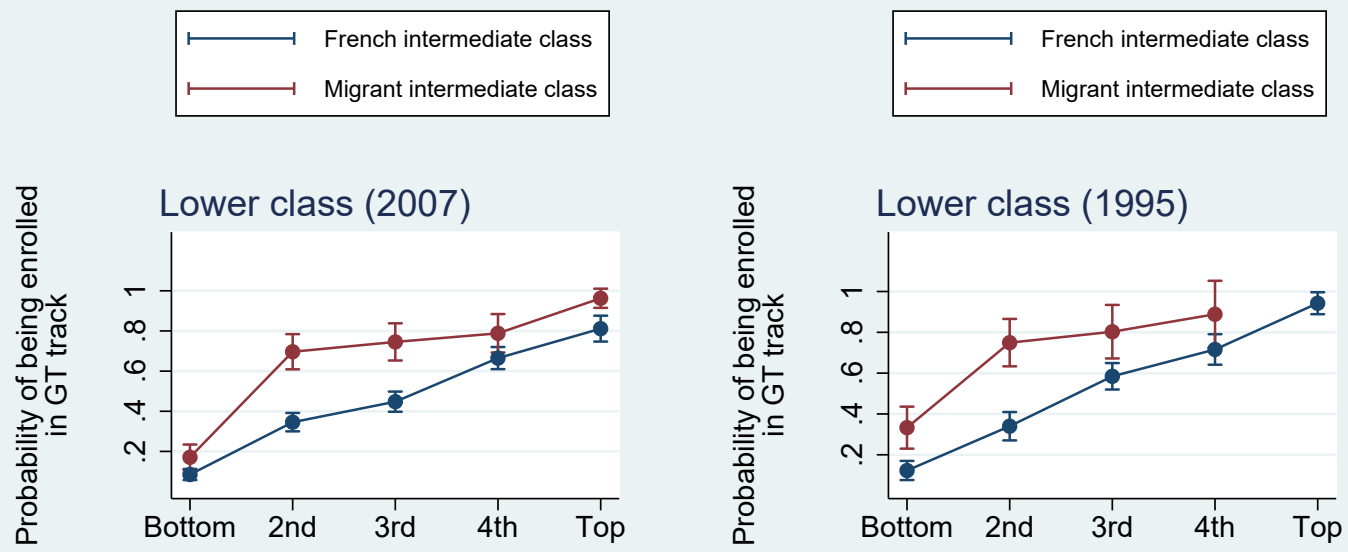

Quintiles of lower secondary grades

Quintiles of lower secondary grades
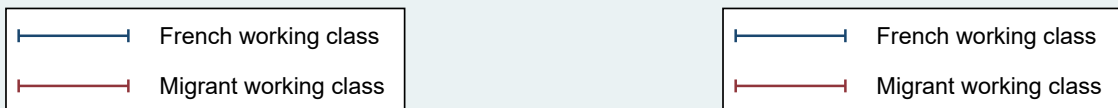

Notes: The figure shows predicted probabilities of enrollment in the general and technological track after compulsory education from logistic models including 3-way interactions of students' immigrant background, parental occupational class and quintiles of school grades in the last year of lower secondary education, and controlling for students' gender, number of siblings, whether they lived with both of their parents, a measure of parental education and indicators for whether students repeated a grade in lower secondary or primary education. Results are presented by comparing immigrant and native students in each social class and by quintiles of lower secondary grades. Estimates are presented with 95 percent confidence intervals.

Source: Panel d'élèves du second degré 2007 and 1995 cohorts, own calculations. 


\section{Appendix D - Presenting counferfactual weights and robustness checks}

I begin this section by presenting the three set of weights used in the analyses in Figure D1. Primary weights compensate for the lower performance of immigrant-origin students and especially their greater likelihood of being in the lowest quintile of the distribution. The range of simple secondary weights is narrower and all weights are all below 1 , since immigrant-origin students are more likely to enroll in the secondary GT track at all levels of performance. Triple interaction weights differ substantively from secondary weights because immigrant-native gaps in enrolment decisions vary significantly by class other than by performance. Figure D1 shows that secondary weights underweigh upper-class immigrant students and overweigh lower-class immigrant-origin students, especially at lower levels of previous performance.

Figure D1: Plot of counterfactual weights applied to immigrant-origin students in counterfactual analyses, 2007 cohort

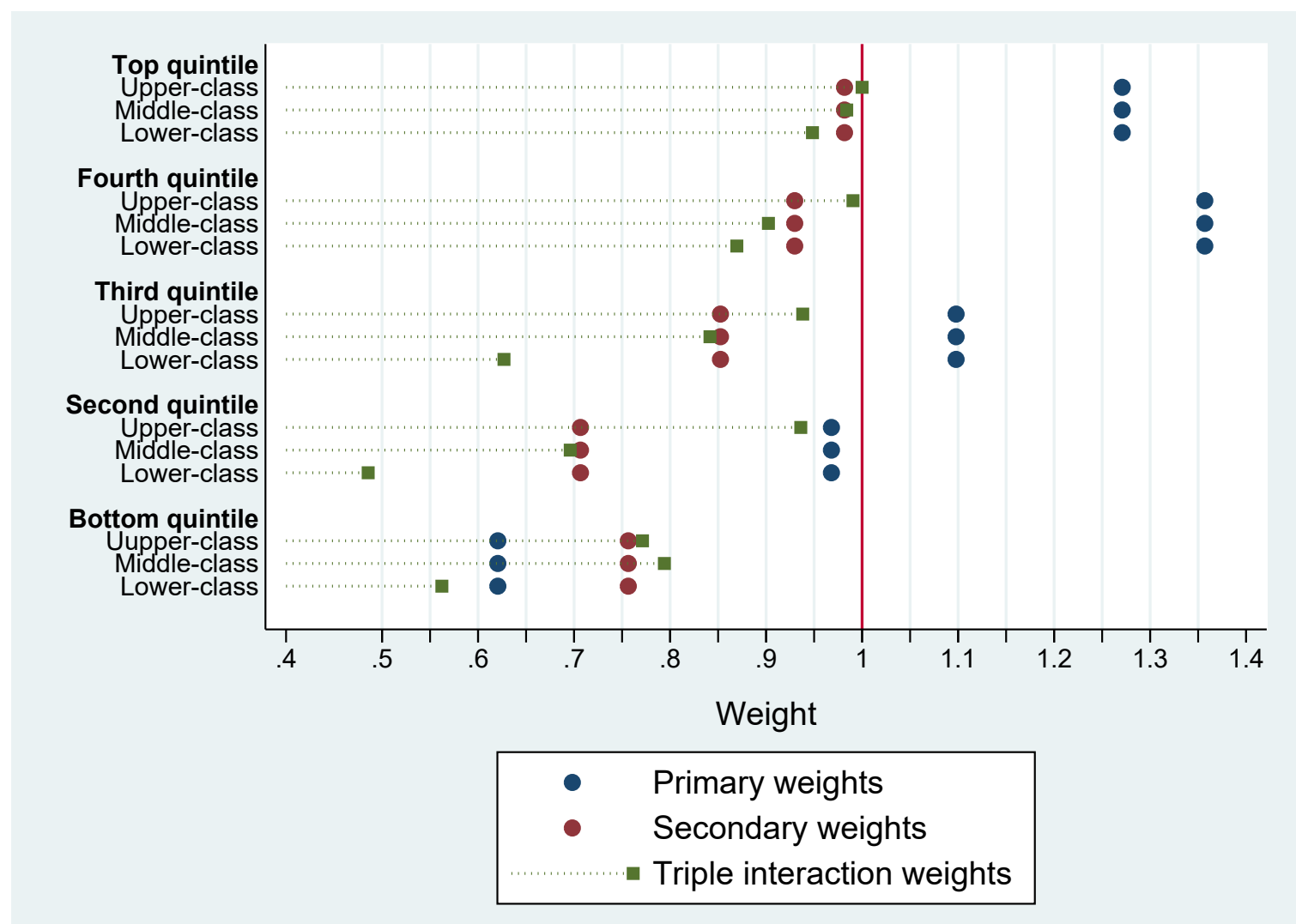

Notes: The figure represents the three set of weights used in the analyses. All weights are created using predicted probabilities computed from logistic regressions. For a detailed explanation refer to the methods section of the paper Source: Panel d'élèves du second degré 2007 cohort, own calculations.

Figure D2 shows how the application of primary and secondary weights change the observed distribution of previous academic achievements among immigrant-origin students enrolled in the GT track. Applying simple secondary weights shifts the counterfactual distribution for immigrant-origin students towards the observed one for native stu- 
dents, by aligning their performance-specific continuation choices. Primary weights simulate the scenario in which immigrant-origin and native students have identical achievement distributions at the end of lower secondary education, but their educational choices are allowed to vary. The application of primary weights is particularly effective at making the counterfactual for immigrant-origin students approach the observed distribution for native students at the lowest and highest levels of previous academic achievement.

Figure D3 compares counterfactual distributions for lower class students obtained from applying secondary weights and triple interaction weights. The counterfactual curve for lower class immigrant-origin students obtained using triple interaction weights is very similar to the observed distribution for lower class native students. In other words, had immigrant-origin students made the same performance- and class-specific enrollment decisions as native students, then their performance distributions would be similar among those enrolled in the GT track. However, both weights have small effects at the lowest level of previous performance.

Figure D2: Distributions of grades at the end of lower secondary education among students enrolled in the general and technologic upper secondary track, 2007 cohort

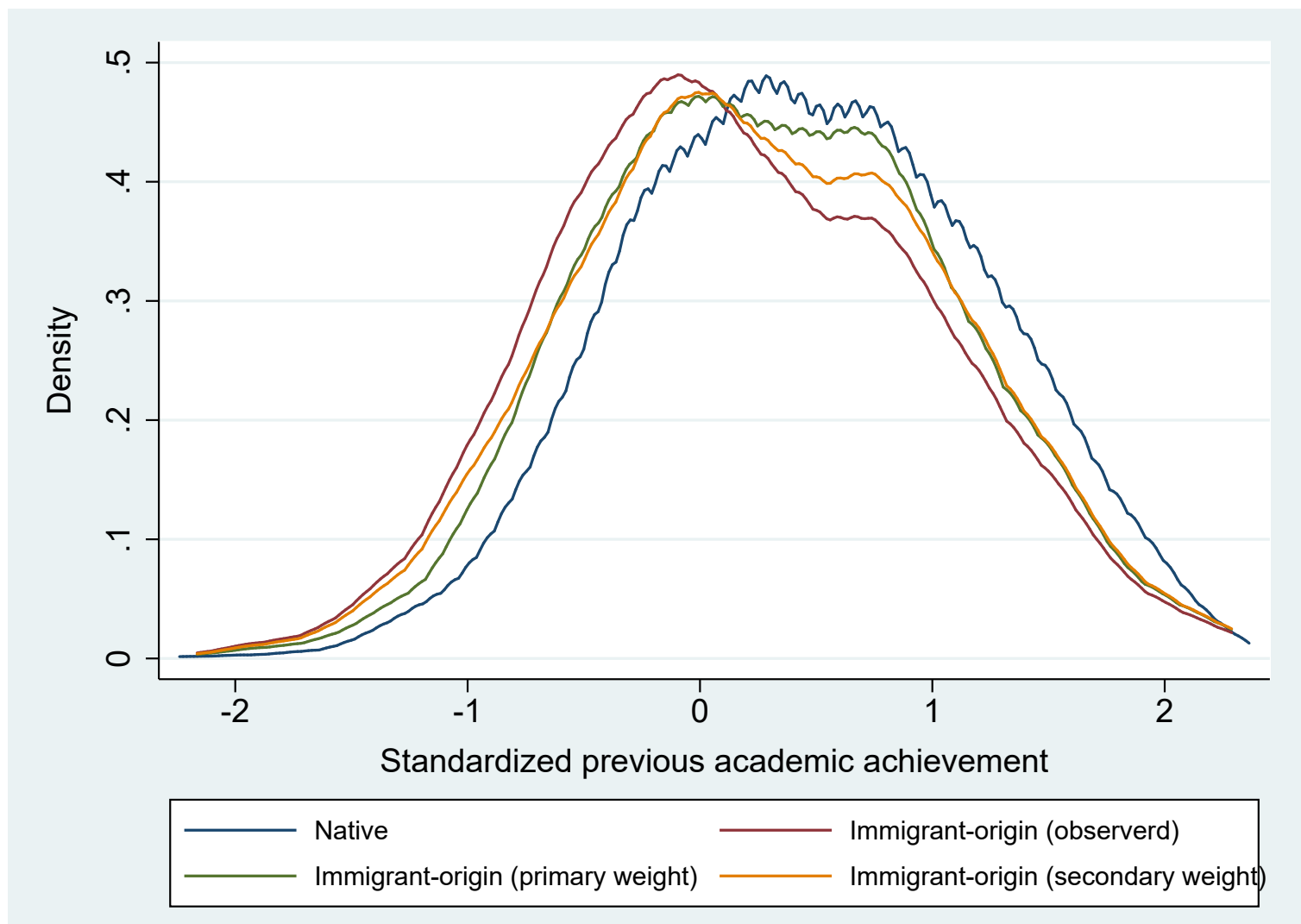

Source: Panel d'élèves du second degré 2007 cohort, own calculations. 
Figure D3: Distributions of grades at the end of lower secondary education among lower class students enrolled in the general and technologic upper secondary track, 2007 cohort

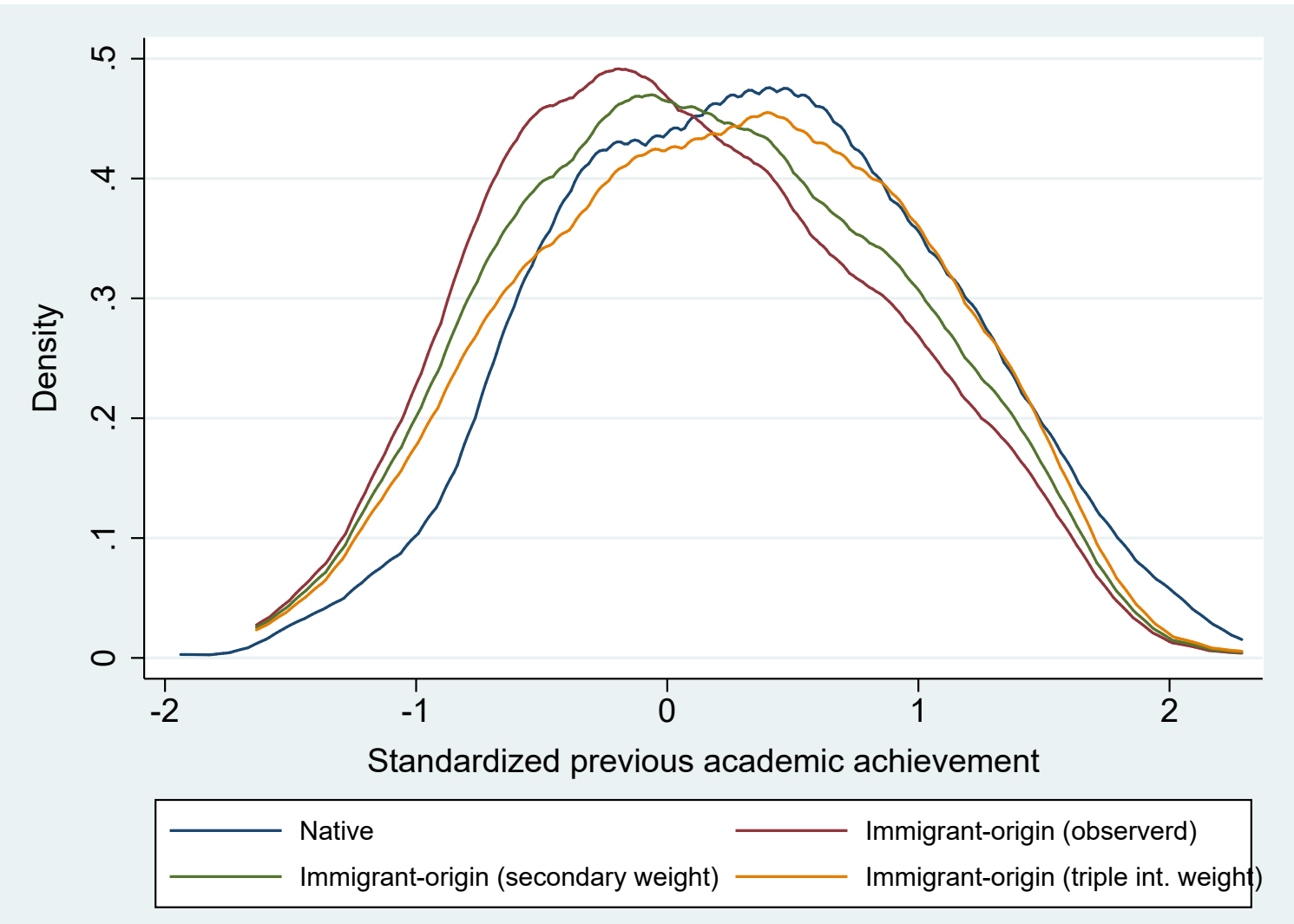

Source: Panel d'élèves du second degré 2007 cohort, own calculations.

In the main results of the paper, counterfactual analyses are run using weights computed from predicted probabilities of enrollment in the GT track obtained from logistic regressions. Specifically, I use point estimates that do not take uncertainty in the estimates into account. This is especially problematic when the confidence intervals on the estimates for immigrant-origin and native students overlap, so that they cannot be considered to be statistically different. I propose two robustness checks to address this concern.

First, I compute a new set of weights in which I assign a value of 1 to categories of immigrant-origin students whose predicted probability of enrollment is not statistically different from the one of native students with the same characteristics. For example, since the confidence intervals of the estimated probability of enrolment in the GT second grade for lower-class immigrant-origin and native students in the lowest quintile of performance overlap, I assign a weight of 1 to immigrant-origin students. In this way, I only assign weights to immigrant-origin students in groups in which immigrant-native differences in predicted probabilities are statistically significant. Figure D4 presents the new set of weights obtained from non-overlapping confidence intervals in the 2007 cohort.

Table D1 and Table D2 present results from counterfactual analyses using the new set of weights. Estimates change only marginally compared to the main analyses and mostly for Models applying triple interaction weights, since these are computed using 
three-way interactions that imply larger uncertainty in estimates.

Figure D4: Plot of counterfactual weights applied to immigrant-origin students obtained from non-overlapping confidence intervals, 2007 cohort

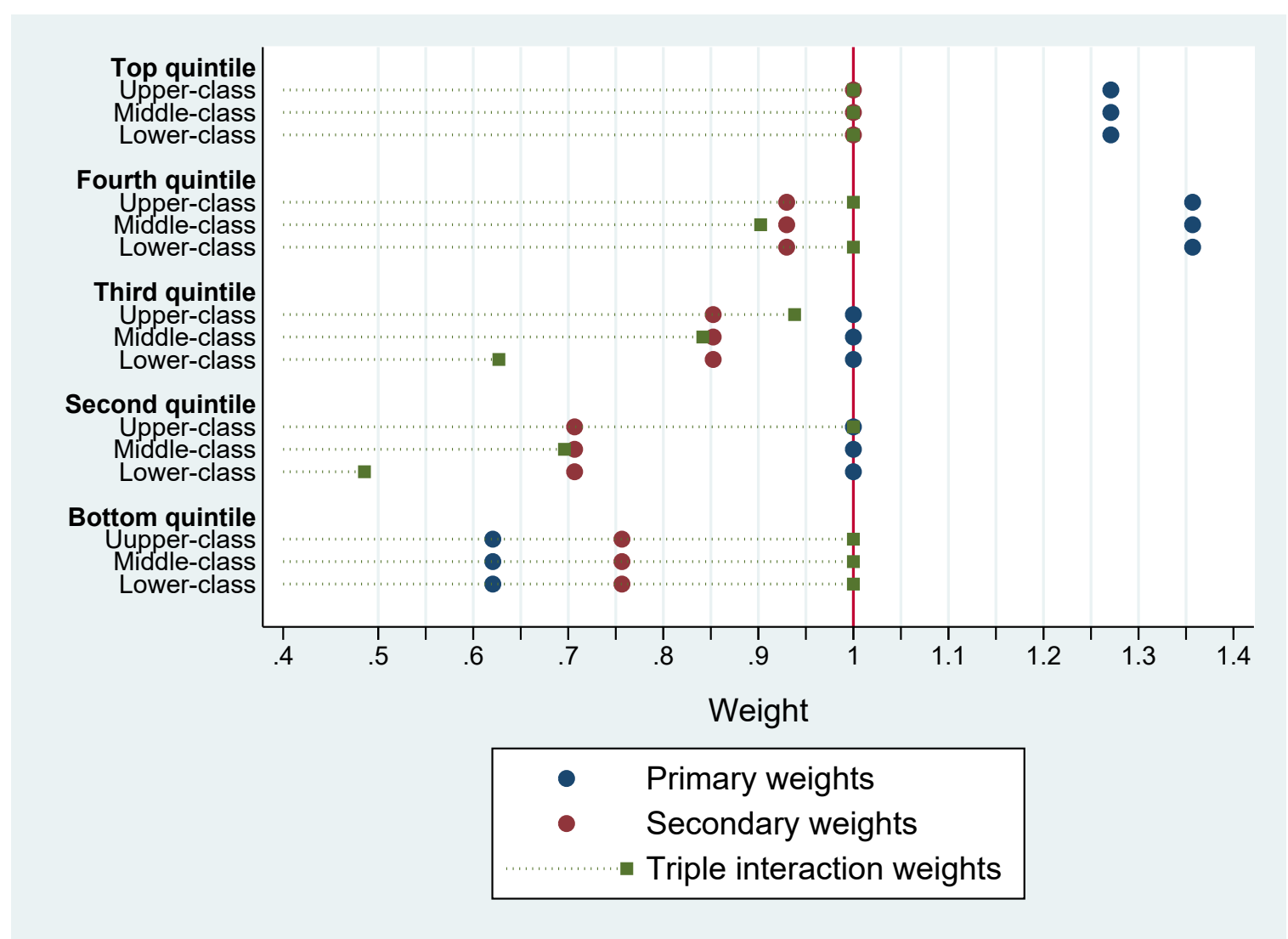

Notes: The figure represents the three set of weights used in the analyses. All weights are created using predicted probabilities computed from logistic regressions. For a detailed explanation refer to the methods section of the paper Source: Panel d'élèves du second degré 2007 cohort, own calculations.

Table D1: Average marginal effects from logistic models predicting outcomes after the first transition into the general and technological upper secondary track using weights from non-overlapping confidence intervals, 2007 cohort

\begin{tabular}{|c|c|c|c|c|c|c|}
\hline & (1) & $(2)$ & $(3)$ & $(4)$ & $(5)$ & $(6)$ \\
\hline & Gross & $\begin{array}{l}\text { Primary } \\
\text { weight }\end{array}$ & $\begin{array}{l}\text { Simple } \\
\text { secondary } \\
\text { weight }\end{array}$ & $\begin{array}{c}\text { Interaction } \\
\text { secondary } \\
\text { weight }\end{array}$ & $\begin{array}{c}+ \text { lowsec } \\
\text { grades }\end{array}$ & $\stackrel{+}{\text { Class }}$ \\
\hline \multicolumn{7}{|c|}{ Panel A: Repeating the first year of upper secondary education } \\
\hline Migrant-native gap & $\begin{array}{c}0.057^{* * *} \\
(0.011)\end{array}$ & $\begin{array}{c}0.034^{* * *} \\
(0.010)\end{array}$ & $\begin{array}{c}0.042^{* * *} \\
(0.010)\end{array}$ & $\begin{array}{c}0.048^{* * *} \\
(0.011)\end{array}$ & $\begin{array}{c}0.021^{*} \\
(0.008)\end{array}$ & $\begin{array}{l}0.023^{* *} \\
(0.009)\end{array}$ \\
\hline Observations & 13437 & 13437 & 13437 & 13437 & 13437 & 13437 \\
\hline Pseudo - $\mathrm{R}^{2}$ & 0.005 & 0.003 & 0.003 & 0.004 & 0.172 & 0.172 \\
\hline \multicolumn{7}{|c|}{ Panel B: Enrollment in the general track in the second transition } \\
\hline Migrant-native gap & $\begin{array}{c}-0.102^{* * *} \\
(0.016)\end{array}$ & $\begin{array}{c}-0.060^{* * *} \\
(0.016)\end{array}$ & $\begin{array}{c}-0.070^{* * *} \\
(0.016)\end{array}$ & $\begin{array}{c}-0.070^{* * *} \\
(0.016)\end{array}$ & $\begin{array}{l}-0.015 \\
(0.013)\end{array}$ & $\begin{array}{c}0.008 \\
(0.013) \\
\end{array}$ \\
\hline Observations & 13437 & 13437 & 13437 & 13437 & 13437 & 13437 \\
\hline Pseudo - $\mathrm{R}^{2}$ & 0.005 & 0.004 & 0.004 & 0.004 & 0.226 & 0.245 \\
\hline
\end{tabular}

Notes: The table reports average marginal effects from logistic regressions with standard errors in parentheses. All Models control for students' gender. Model 1 presents gross gaps. Model 2 estimates Model 1 with primary counterfactual weights. Model 3 estimates Model 1 with secondary weights. Model 4 estimates Model 1 with triple interaction weights. Model 5 adds controls for students' quintile of compulsory school grades before making the transition to Model 4. Model 6 adds controls for parental occupational class to Model 5 .

${ }^{*} p<0.05,{ }^{* *} p<0.01,{ }^{* * *} p<0.001$.

Source: Panel d'élèves du second degré 2007 cohort, own calculations. 
Table D2: Average marginal effects from logistic models predicting outcomes after the first transition into the general and technological upper secondary track using weights from non-overlapping confidence intervals, 2007 cohort

\begin{tabular}{|c|c|c|c|c|c|c|}
\hline & Gross & $\begin{array}{c}(2) \\
\text { Primary } \\
\text { weight }\end{array}$ & $\begin{array}{c}(3) \\
\text { Simple } \\
\text { secondary } \\
\text { weight }\end{array}$ & $\begin{array}{c}(4) \\
\text { Interaction } \\
\text { secondary } \\
\text { weight }\end{array}$ & $\begin{array}{c}(5) \\
+ \text { lowsec } \\
\text { grades }\end{array}$ & $\stackrel{+}{+}$ \\
\hline \multicolumn{7}{|c|}{ Panel A: Repeating the first year of upper secondary education } \\
\hline Migrant-native gap & $\begin{array}{l}0.046^{*} \\
(0.023)\end{array}$ & $\begin{array}{c}0.024 \\
(0.022)\end{array}$ & $\begin{array}{c}0.025 \\
(0.021)\end{array}$ & $\begin{array}{c}0.019 \\
(0.021)\end{array}$ & $\begin{array}{l}-0.015 \\
(0.018)\end{array}$ & $\begin{array}{l}-0.022 \\
(0.019)\end{array}$ \\
\hline Observations & 5832 & 5832 & 5832 & 5832 & 5832 & 5832 \\
\hline Pseudo - $\mathrm{R}^{2}$ & 0.004 & 0.003 & 0.003 & 0.003 & 0.137 & 0.138 \\
\hline \multicolumn{7}{|c|}{ Panel B: Enrollment in the general track in the second transition } \\
\hline Migrant-native gap & $\begin{array}{c}-0.204^{* * *} \\
(0.027) \\
\end{array}$ & $\begin{array}{c}-0.160^{* * *} \\
(0.028)\end{array}$ & $\begin{array}{c}-0.164^{* * *} \\
(0.027) \\
\end{array}$ & $\begin{array}{c}-0.144^{* * *} \\
(0.028)\end{array}$ & $\begin{array}{c}-0.082^{* * *} \\
(0.023) \\
\end{array}$ & $\begin{array}{l}-0.015 \\
(0.023) \\
\end{array}$ \\
\hline Observations & 5832 & 5832 & 5832 & 5832 & 5832 & 5832 \\
\hline Pseudo - $\mathrm{R}^{2}$ & 0.017 & 0.014 & 0.013 & 0.012 & 0.180 & 0.214 \\
\hline \multicolumn{7}{|c|}{ Panel C: Completion of the general or the technological track } \\
\hline Migrant-native gap & $\begin{array}{c}-0.077^{* * *} \\
(0.021)\end{array}$ & $\begin{array}{c}-0.056^{* *} \\
(0.020)\end{array}$ & $\begin{array}{c}-0.059^{* *} \\
(0.020)\end{array}$ & $\begin{array}{c}-0.059^{* *} \\
(0.021)\end{array}$ & $\begin{array}{l}-0.026 \\
(0.017)\end{array}$ & $\begin{array}{l}-0.004 \\
(0.017)\end{array}$ \\
\hline Observations & 5832 & 5832 & 5832 & 5832 & 5832 & 5832 \\
\hline Pseudo - $\mathrm{R}^{2}$ & 0.007 & 0.005 & 0.005 & 0.005 & 0.113 & 0.122 \\
\hline \multicolumn{7}{|c|}{ Panel D: Completion of the general track } \\
\hline Migrant-native gap & $\begin{array}{c}-0.208^{* * *} \\
(0.027)\end{array}$ & $\begin{array}{c}-0.161^{* * *} \\
(0.028)\end{array}$ & $\begin{array}{c}-0.170^{* * *} \\
(0.027)\end{array}$ & $\begin{array}{c}-0.153^{* * *} \\
(0.028)\end{array}$ & $\begin{array}{c}-0.088^{* * *} \\
(0.024)\end{array}$ & $\begin{array}{l}-0.021 \\
(0.024)\end{array}$ \\
\hline Observations & 5832 & 5832 & 5832 & 5832 & 5832 & 5832 \\
\hline Pseudo - $\mathrm{R}^{2}$ & 0.016 & 0.013 & 0.012 & 0.012 & 0.190 & 0.222 \\
\hline
\end{tabular}

Notes: The table reports average marginal effects from logistic regressions with standard errors in parentheses. All Models control for students' gender. Model 1 presents gross gaps. Model 2 estimates Model 1 with primary counterfactual weights. Model 3 estimates Model 1 with secondary weights. Model 4 estimates Model 1 with triple interaction weights. Model 5 adds controls for students' quintile of compulsory school grades before making the transition to Model 4. Model 6 adds controls for parental occupational class to Model 5.

$* p<0.05,{ }^{* *} p<0.01,{ }^{* * *} p<0.001$.

Source: Panel d'élèves du second degré 2007 cohort, own calculations.

The second strategy I propose, is to compute bounds on the estimated effects in the couterfactual analyses by using the extremes of the confidence intervals of the estimated predicted probabilities used to compute weights. This strategy is straightforward for simple and triple interaction weights because the probability of enrolment in the GT track is consistently higher for immigrant-origin students. To compute the upper bound on the estimates of upper secondary effects, I compute simple and triple interaction weights by using the upper extreme of the confidence interval of the probability of enrolment for immigrant-origin students and the minimum of the confidence interval for native students. To compute the lower bound, I do the opposite: I take the minimum of the confidence interval for immigrant-origin students and the maximum for native students.

For primary weights, the strategy is different because immigrant-origin students are more likely to be in the lowest quintiles of academic performance but less likely to be in the top ones. I adopt the following technique: to compute an upper bound, I take the maximum of the confidence interval for immigrant-origin students in the lowest two quintiles and the minimum for the top two, but I keep the point estimate for the middle one, and I do the opposite for native students. To compute a lower bound, I do the opposite: I take the minimum of the confidence interval for immigrant-origin students in 
the lowest two quintiles and the maximum for the top two, but I keep the point estimate for the middle one, and I do the opposite for native students.

Results presented in Figure D5 and D6 show that estimated immigrant-natives gaps with counterfactual weights vary depending on the estimates used to compute the weights. This is especially true for primary weights and triple interaction weights. For the latter, this is related to the large uncertainty on some of the estimates used for computing weights due to small sample sizes. For the former, this could be related to the different method used to compute the bounds, which makes the bounds more extreme. For secondary weights, upper and lower bounds are relatively close because estimates used to compute them are relatively precise.

Figure D5: Immigrants-natives gaps in outcomes after the first transition in the general and technological upper secondary track obtained from counterfactual analyses using bounds in counterfactual weights, 2007 cohort

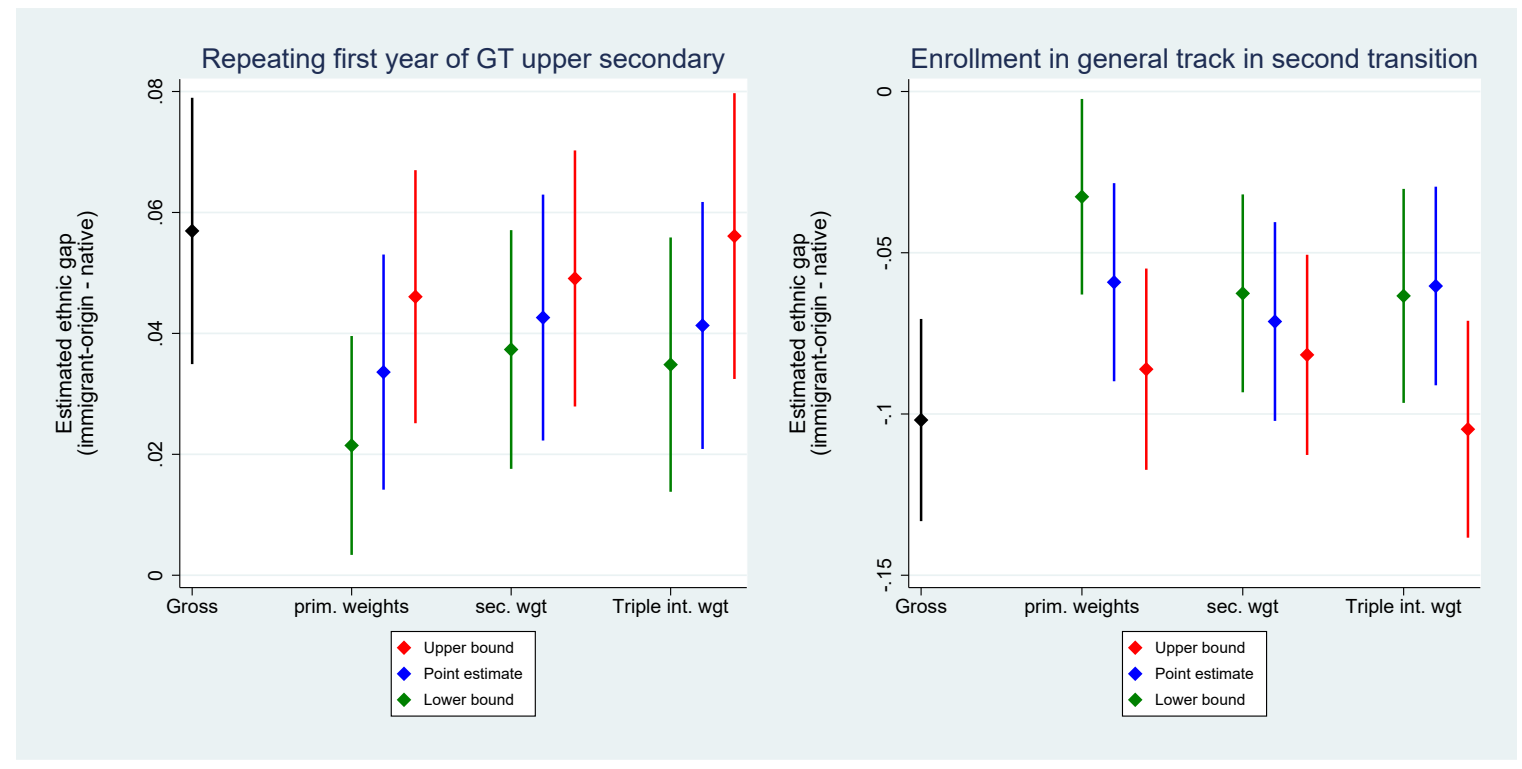

Notes: The figure reports average marginal effects from logistic regressions of upper secondary education outcomes on an indicator for immigrant background. The gross ethnic gap is obtained from the unweigthed regression, whereas the others are obtained from the same regression by applying primary, secondary or triple interaction weights computed using either point estimates, upper bounds or lower bounds in predicted probabilities. Estimates are presented with 95 percent confidence intervals.

Source: Panel d'élèves du second degré 2007 cohort, own calculations. 
Figure D6: Immigrants-natives gaps in outcomes after the first transition in the general and technological upper secondary track obtained from counterfactual analyses using bounds in counterfactual weights, 1995 cohort
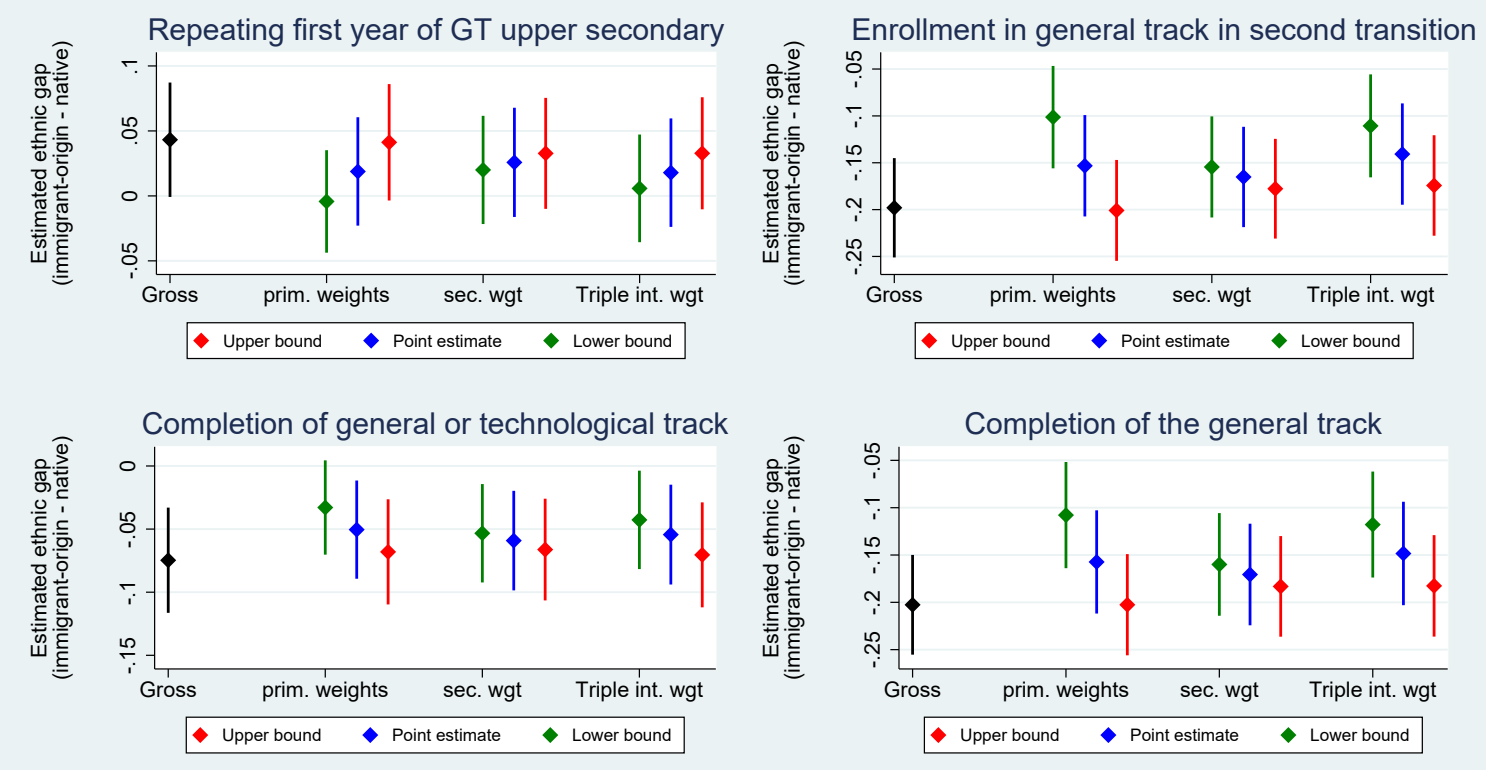

Notes: The figure reports average marginal effects from logistic regressions of upper secondary education outcomes on an indicator for immigrant background. The gross ethnic gap is obtained from the unweigthed regression, whereas the others are obtained from the same regression by applying primary, secondary or triple interaction weights computed using either point estimates, upper bounds or lower bounds in predicted probabilities. Estimates are presented with 95 percent confidence intervals.

Source: Panel d'élèves du second degré 2007 and 1995 cohorts, own calculations. 